\title{
Strategic approach to developing a self-
}

\section{microemulsifying drug delivery system to enhance antiplatelet activity and bioavailability of ticagrelor}

This article was published in the following Dove Medical Press journal: International Journal of Nanomedicine

\author{
Young-Guk $\mathrm{Na}$ \\ Jin-Ju Byeon' \\ Miao Wang' \\ Hyun Wook Huh' \\ Gi-Ho Son ${ }^{1,2}$ \\ Sung-Hoon Jeon ${ }^{1,3}$ \\ Ki-Hyun Bang ${ }^{1,2}$ \\ Sung-Jin Kim' \\ Hye-Jin Lee' \\ Hong-Ki Lee' \\ Cheong-Weon Cho' \\ 'College of Pharmacy, Chungnam \\ National University, Daejeon, \\ Republic of Korea; ${ }^{2}$ Korea \\ United Pharmaceutical Co. Ltd., \\ Sejong, Republic of Korea; ${ }^{3}$ SamA \\ Pharmaceutical Co. Ltd., Suwon, \\ Republic of Korea
}

Background: Ticagrelor (TCG) is used to inhibit platelet aggregation in patients with acute coronary syndrome, but its poor solubility and low bioavailability limit its in vivo efficacy. The purpose of this study was to manufacture an optimized TCG-loaded self-microemulsifying drug delivery system (SMEDDS) to enhance the oral bioavailability and antiplatelet activity of TCG. Materials and methods: Solubility and emulsification tests were conducted to determine the most suitable oils, surfactants, and cosurfactants. Scheffé's mixture design was applied to optimize the percentage of each component applied in the SMEDDS formulation to achieve optimal physical characteristics, ie, high solubility of TCG in SMEDDS, small droplet size, low precipitation, and high transmittance.

Results: The optimized TCG-loaded SMEDDS (TCG-SM) formulation composed of $10.0 \%$ Capmul MCM (oil), 53.8\% Cremophor EL (surfactant), and 36.2\% Transcutol P (cosurfactant) significantly improving the dissolution of TCG in various media compared with TCG in Brilinta ${ }^{\circledR}$ (commercial product). TCG-SM exhibited higher cellular uptake and permeability in Caco-2 cells than raw TCG suspension. In pharmacokinetic studies in rats, TCG-SM exhibited higher oral bioavailability with 5.7 and 6.4 times higher area under the concentration-time curve and maximum plasma concentration, respectively, than a raw TCG suspension. Antiplatelet activity studies exhibited that the TCG-SM formulation showed significantly improved inhibition of platelet aggregation compared with raw TCG at the same dose of TCG. And, a $10 \mathrm{mg} / \mathrm{kg}$ dose of raw TCG suspension and a $5 \mathrm{mg} / \mathrm{kg}$ dose of TCG-SM had a similar area under the inhibitory curve $(907.0 \% \pm 408.8 \%$ and $907.8 \% \pm 200.5 \%$ hours, respectively) for antiplatelet activity. Conclusion: These results suggest that the developed TCG-SM could be successfully used as an efficient method to achieve the enhanced antiplatelet activity and bioavailability of TCG.

Keywords: ticagrelor, SMEDDS, optimization, bioavailability, platelet aggregation, antiplatelet activity

\section{Introduction}

Ticagrelor (TCG), a cyclopentyl-triazolo-pyrimidine, belongs to a class of chemically noncompetitive and reversible antagonists of the platelet $\mathrm{P} 2 \mathrm{Y}_{12}$ ADP receptor. ${ }^{1-4} \mathrm{TCG}$ was approved for use in patients with acute coronary syndrome based on a phase III study (Platelet Inhibition and Patient Outcomes), which showed a significant benefit compared with clopidogrel. ${ }^{5,6}$ However, TCG exhibits very low solubility $(<10 \mu \mathrm{g} / \mathrm{mL})$ at all $\mathrm{pH}$ values. It also has low intestinal membrane permeability corresponding to Biopharmaceutical Classification System (BCS) class IV. Because of these properties of TCG, the absolute bioavailability of TCG after oral administration is $36 \%$. ${ }^{7}$ Although formulations to enhance the bioavailability and antiplatelet activity of TCG, 
such as solid dispersion ${ }^{8}$ and cocrystallization, ${ }^{9}$ have recently been reported, few studies have been performed.

We developed a self-microemulsifying drug delivery system (SMEDDS) to overcome the above barriers and enhance the antiplatelet activity of TCG. SMEDDS have recently attracted interest for the oral delivery of insoluble drugs because of their ease of manufacture and their practical advantages in improving drug solubility and oral bioavailability. ${ }^{10-12}$ They have been applied to BCS class II or IV drugs such as atorvastatin, valsartan, lopinavir, nelfinavir, and tamoxifen citrate. ${ }^{12-16}$ A SMEDDS formulation is a stable, single-phase, and isotropic mixture of oil, surfactant, and cosurfactant without an aqueous phase. It forms an oil-inwater $(\mathrm{o} / \mathrm{w})$ microemulsion with a globule size in the range of 20-200 nm when dispersed in the gastrointestinal tract via gentle gastric motility or in an aqueous phase after oral administration. ${ }^{17}$ This self-formed microemulsion transports the drug in solubilized form. The small droplet size of the microemulsion provides large surface area for rapid dissolution and absorption of the drug, which increases the permeability of the drug through the intestinal membrane. Other potential advantages of using SMEDDS to improve the oral bioavailability of poor water-soluble drugs are their promotion of transcellular and paracellular absorption, reduction of metabolism of CYP/CYP450 by gastrointestinal enzymes, and enhancement of lymphatic transport, all of which can protect the drug from first-pass metabolism. ${ }^{18-21}$

In this study, we developed and optimized a TCG-loaded SMEDDS (TCG-SM) formulation by design of experiments using Scheffé's mixture design based on a small number of trials and response surface methodology. We also characterized the optimized TCG-SM, evaluated its in vitro dissolution, performed cellular studies, and compared its antiplatelet activity and pharmacokinetics with those of a raw TCG suspension.

\section{Materials and methods Materials}

TCG was supplied by Korea United Pharm Inc. (Seoul, Republic of Korea). Tween 20 (polyoxyethylene sorbitan monolaurate), Tween 80 (polyoxyethylene sorbitan monooleate), olive oil, castor oil, oleic acid, mineral oil, sunflower oil, cotton seed oil, linseed oil, Span 80 (sorbitan monooleate), and polyethylene glycol 400 (PEG 400) were purchased from Samchun Chemical Co., Ltd (Pyeongtaek, Republic of Korea). Labrafac CC (medium-chain triglycerides), Lauroglycol FCC (propylene glycol monolaurate, type I), Lauroglycol 90 (propylene glycol monolaurate, type II), Peceol (glycerol monooleates, type 40), Labrafac Lipophile WL 1349 (medium-chain triglycerides), Labrafil M 2125 CS (linoleoyl macrogol-6 glycerides), Labrafil M 1944 CS (oleoyl macrogol-6 glycerides), Capryol PGMC (propylene glycol monocaprylate, type I), Capryol 90 (propylene glycol monocaprylate, type II), Labrasol (caprylocaproyl macrogol-8 glycerides), and Transcutol P (diethylene glycol monoethyl) were kindly provided by Gattefossé Co. (Lyon, France). Capmul MCM (glyceryl caprylate/caprate) was provided by ABITEC Corporation (Cleveland, $\mathrm{OH}$, USA). Lecithin, isopropyl palmitate, and isopropyl myristate were purchased from Tokyo Chemical Industries Co., Ltd. (Toshima, Japan). Span 83 (sorbitan sesquioleate), Span 85 (sorbitan trioleate), tetraglycol, propylene glycol, DMSO, MTT, and ethylenediaminetetraacetic acid were purchased from Sigma-Aldrich (St Louis, MO, USA). Pluronic L64 (triblock copolymer- $\mathrm{EO}_{13} \mathrm{PO}_{30} \mathrm{EO}_{13}$ ) and Cremophor EL (polyoxyl 35 hydrogenated castor oil) were obtained as a gift from BASF Co. (Ludwigshafen, Germany). The HPLC-grade acetonitrile and methanol were purchased from JT Baker (Phillipsburg, NJ, USA). All other chemicals and solvents used in this study were of analytical grade. Distilled water was used throughout the experiments.

\section{HPLC analysis}

The HPLC analysis of TCG was carried out by modifying a method described previously. ${ }^{22}$ An Agilent 1100 series LC model (Agilent Technologies Inc., Santa Clara, CA, USA), equipped with a pump, autosampler, thermostat, and UV-Vis detector was used for analysis. An Xterra RP18 column $(250 \times 4.6 \mathrm{~mm}, 5 \mu \mathrm{m}$; Waters, Milford, MA, USA) was used for the analysis of TCG. The isocratic mobile phase consisted of acetonitrile and $50 \mathrm{nM}$ ammonium acetate buffer $(58: 42, \mathrm{v} / \mathrm{v})$. The $\mathrm{pH}$ of the mobile phase was adjusted to 8.2 with $6 \mathrm{M}$ ammonium hydroxide. The flow rate was $1.0 \mathrm{~mL} / \mathrm{min}$, sample injection volume was $20 \mu \mathrm{L}$, and the column temperature kept constant at $40^{\circ} \mathrm{C}$. The wavelength for ultraviolet detection of TCG was $254 \mathrm{~nm}$.

\section{Preliminary screening of excipients for SMEDDS}

To select a suitable oil, surfactant, and cosurfactant for the SMEDDS of TCG, the solubility of TCG in various excipients was determined by equilibrium solubility. Equilibrium solubility studies on TCG were carried out in various oils (Capryol 90, Capryol PGMC, Capmul MCM, Labrafil M 1944 CS, Labrafil M 2125 CS, Labrafac Lipophile WL 1349, Peceol, Lauroglycol 90, Lauroglycol FCC, Labrafac CC, 
isopropyl myristate, isopropyl palmitate, linseed oil, cotton seed oil, sunflower oil, mineral oil, oleic acid, castor oil, and olive oil), surfactants (Cremophor EL, Pluronic L64, Labrasol, Tween 80, and Tween 20), and cosurfactants (propylene glycol, tetraglycol, Transcutol P, and PEG 400). Briefly, an excess amount of the drug was added to different vials containing $1 \mathrm{~g}$ of each excipient and mixed for 72 hours to reach saturation at $25^{\circ} \mathrm{C}$ using an angle rotator (model AG; FinePCR, Gunpo, Republic of Korea) with $15 \mathrm{rpm}$. The saturated mixtures were centrifuged at $15,000 \times g$ for 15 minutes at $25^{\circ} \mathrm{C}$ to remove the excess TCG. The supernatant was filtered through a $0.45 \mu \mathrm{m}$ polyvinylidene fluoride (PVDF) membrane (Millipore, Bengaluru, Karnataka, India), and the filtered solution was diluted 100 times with isopropanol. The TCG concentration was then measured by HPLC analysis.

\section{Evaluation of emulsification and phase separation}

The evaluation of emulsification was carried out for the preselected excipients to determine the most appropriate surfactant and cosurfactant. Based on the requirement for a self-forming microemulsion, a type IV composition was used, which dispersed very finely and formed small droplets. ${ }^{23}$ The SMEDDS formulations were prepared with a composition of $20 \%$ oil, $40 \%$ surfactant, and $40 \%$ cosurfactant, and $100 \mathrm{mg}$ SMEDDS was diluted in $10 \mathrm{~mL}$ of distilled water or media at $\mathrm{pH} 1.2, \mathrm{pH}$ 4.0, or $\mathrm{pH}$ 6.8. Subsequently, the mixture was homogenized for 30 minutes and then evaluated for emulsification and phase separation. The emulsification grade of SMEDDS was classified by the droplet size, transmittance, and phase separation (Table S1, Supplementary materials) by modifying the previously reported grading system. ${ }^{12}$ The phase separation was visually confirmed by the presence or absence of precipitation.

\section{Pseudoternary phase diagram}

The pseudoternary phase diagram was used to determine the ranges of the microemulsions. Based on the solubility studies and emulsification results for each excipient, the ternary phase diagrams were plotted by combining various percentages of Capmul MCM (oil), Cremophor EL or Tween 20 (surfactant), and Transcutol P (cosurfactant). The vertices of the triangle graph corresponded to each component. For any mixture, the total percentage of oil, surfactant, and cosurfactant was $100 \%$. One hundred milligrams of each mixture were added to $10 \mathrm{~mL}$ distilled water and gently stirred using a magnetic stirrer to evaluate microemulsionforming ability. The droplet size, transmittance, and phase separation of the microemulsion formed were measured.
A mixture that formed a transparent microemulsion with droplets $<300 \mathrm{~nm}$ (grade A and B as described in method; Evaluation of emulsification and phase separation) was considered a suitable SMEDDS formulation. All studies were repeated in triplicate.

\section{Experimental optimization of TCG-SM formulation}

The composition of the SMEDDS formulation was optimized using Scheffé's mixture design, which is desirable for response surface methodology to optimize complex formulations. ${ }^{24}$ The experiments were designed using three factors and four responses (Table 1). Design-Expert ${ }^{\circledR} 11$ (Stat-Ease Inc., Minneapolis, MN, USA) was used to perform the experimental design and statistical analysis.

The experimental design and statistical analysis were performed using Design-Expert 11 (Stat-Ease Inc.). Based on pseudoternary phase diagram, the percentages of Capmul $\operatorname{MCM}\left(\mathrm{X}_{1}, \mathrm{w} / \mathrm{w} \%\right)$, Cremophor EL $\left(\mathrm{X}_{2}, \mathrm{w} / \mathrm{w} \%\right)$, and Transcutol $\mathrm{P}\left(\mathrm{X}_{3}, \mathrm{w} / \mathrm{w} \%\right)$ were set within ranges of $10 \%-40 \%$, $10 \%-80 \%$, and $10 \%-80 \%$, respectively. In all experiments, the percentages of $\mathrm{X}_{1}, \mathrm{X}_{2}$, and $\mathrm{X}_{3}$ added up to $100 \%$. The solubility of TCG in SMEDDS $\left(Y_{1}\right)$, the precipitation of TCG $\left(\mathrm{Y}_{2}\right)$, droplet size $\left(\mathrm{Y}_{3}\right)$, and transmittance $\left(\mathrm{Y}_{4}\right)$ were used as responses to optimize the SMEDDS composition. The 17 designed experiments were fitted to linear, cubic, quadratic, and special cubic or quadratic polynomial models. The appropriate fitting model for each response was determined by comparing various statistical parameters provided by ANOVAs, such as sequential $P$-values, lack of fit, squared correlation coefficient $\left(R^{2}\right)$, adjusted $R^{2}$, and adequate precision. The desirability function was analyzed for the optimization of factors associated with desirable responses after the fitting of the statistical model.

Table I Factors and responses used in Scheffé's mixture design

\begin{tabular}{|l|l|l|}
\hline \multirow{2}{*}{ Factors } & \multicolumn{2}{|l|}{ Range } \\
\cline { 2 - 3 } & $\begin{array}{l}\text { Low limit } \\
(\mathbf{w} / \mathbf{w} \%)\end{array}$ & $\begin{array}{l}\text { High limit } \\
\text { (w/w \%) }\end{array}$ \\
\hline $\mathrm{X}_{1}:$ Capmul MCM (oil) & 10 & 40 \\
\hline $\mathrm{X}_{2}:$ Cremophor EL (surfactant) & 10 & 80 \\
\hline $\mathrm{X}_{3}:$ Transcutol P (cosurfactant) & 10 & 80 \\
\hline Responses & \multicolumn{2}{|c|}{ Goal } \\
\hline$Y_{1}:$ Solubility $(\mathrm{mg} / \mathrm{mL})$ & \multicolumn{2}{|c|}{ Maximize } \\
\hline$Y_{2}:$ Precipitation $(\%)$ & \multicolumn{2}{|c|}{ Minimize } \\
\hline$Y_{3}:$ Droplet size $(\mathrm{nm})$ & \multicolumn{2}{|c|}{ Minimize } \\
\hline$Y_{4}:$ Transmittance $(\%)$ & \multicolumn{2}{|c|}{ Maximize } \\
\hline
\end{tabular}




\section{Solubility of TCG in SMEDDS $\left(\mathrm{Y}_{1}\right)$}

The solubility of TCG in SMEDDS was evaluated to prepare a formulation capable of dissolving a large amount of TCG in the minimum volume of SMEDDS formulation. Solubility measurements were conducted by modifying the method for screening excipients (see method; Preliminary screening of excipients for SMEDDS). In brief, excess TCG was added to $1 \mathrm{~g}$ of prepared SMEDDS and the solubility was measured after stirring for 72 hours. The samples were centrifuged at $15,000 \times g$ for 15 minutes at $25^{\circ} \mathrm{C}$, the supernatant was diluted with isopropanol, and TCG measured by HPLC.

\section{Precipitation $\left(\mathrm{Y}_{2}\right)$}

A precipitation test was performed to confirm that the microemulsion formed homogeneous droplets $<200 \mathrm{~nm}$ in diameter. Briefly, $10 \mathrm{~mL}$ of distilled water was added to $100 \mathrm{mg}$ of the TCG-SM, and the mixture was vortexed for 30 minutes to form a homogeneous microemulsion. The microemulsion was filtered through a $0.22 \mu \mathrm{m}$ PVDF membrane filter, immediately diluted with isopropanol, and analyzed by HPLC. The degree of precipitation was evaluated by comparing the TCG concentration with that of TCG-SM dissolved in isopropanol. The equation used is as follows:

$$
\text { Precipitation }(\%)=100 \times\left(1-\frac{\mathrm{C}_{\mathrm{w}}}{\mathrm{C}_{\mathrm{p}}}\right)
$$

where $\mathrm{C}_{\mathrm{w}}$ is the concentration of TCG in TCG-SM diluted with distilled water and $\mathrm{C}_{\mathrm{p}}$ is the concentration of TCG in TCG-SM diluted in isopropanol. A precipitation percentage close to $0 \%$ indicates that the precipitation of TCG does not occur.

\section{Droplet size $\left(\mathrm{Y}_{3}\right)$}

The SMEDDS droplet size was measured after the reconstitution procedure. One hundred milligrams of SMEDDS were added to $10 \mathrm{~mL}$ of distilled water to prepare a reconstituted microemulsion. The microemulsion was subsequently incubated for 30 minutes at room temperature. The samples were loaded into a cuvette and then monitored with an electrophoretic laser scattering (ELS) analyzer (ELS-8000; Otsuka Electronics, Osaka, Japan). The instrument was set to measure the droplet size 50 times and calculate the average size.

\section{Transmittance $\left(\mathrm{Y}_{4}\right)$}

The transmittance of each mixture was determined by measuring the absorbance of the formulation at $620 \mathrm{~nm}$ using a microplate reader (Sunrise; Tecan Group Ltd., Männedorf,
Switzerland) compared with distilled water as control. To measure absorbance, $100 \mathrm{mg}$ of each mixture was added to $10 \mathrm{~mL}$ distilled water for forming the microemulsion. The transmittance was calculated using the following equation:

$$
\text { Transmittance }(\%)=100 \times 10^{-A}
$$

where $A$ is the absorbance of microemulsion. A transmittance close to $100 \%$ indicates a clear and transparent microemulsion.

\section{Characterization of TCG-SM}

The optimized TCG-SM was prepared by dissolving $90 \mathrm{mg}$ of TCG in $400 \mathrm{mg}$ of the optimized SMEDDS. The morphology of the TCG-SM was evaluated using a transmission electron microscope (JEM 1400; JEOL Ltd, Tokyo, Japan) with an acceleration voltage of $120 \mathrm{kV}$. The TCG-SM was dispersed in distilled water. Then, $10 \mu \mathrm{L}$ of the sample was directly mounted on a copper grid and dried at room temperature before being observed with the microscope. For droplet size measurements, $100 \mathrm{mg}$ of TCG-SM was suspended by gentle mixing in $10 \mathrm{~mL}$ distilled water for 30 minutes. The droplet size was measured using an ELS analyzer (ELS-8000; Otsuka Electronics).

In vitro dissolution of TCG in the optimized TCG-SM was compared with that of TCG in Brilinta ${ }^{\circledR} 90 \mathrm{mg}$ (commercial product) using the United States Pharmacopeia (USP) apparatus II method with a dissolution tester (DST-810; Labfine, Anyang, Republic of Korea). Distilled water and media at $\mathrm{pH} 1.2, \mathrm{pH} 4.0$, and $\mathrm{pH} 6.8$ were prepared as dissolution media according to the USP guidelines. The volume of dissolution media was $900 \mathrm{~mL}$ with $37^{\circ} \mathrm{C} \pm 0.5^{\circ} \mathrm{C}$. The paddle speed was set at $50 \mathrm{rpm}$ throughout the experiment. The TCG-loaded Cremophor EL (TCG-CE) and TCG-SM containing $90 \mathrm{mg}$ of TCG were filled into hard gelatin capsules (capsule 00 size). The TCG-CE was prepared with the same amount of Cremophor EL as in the TCG-SM formulation to compare the effect of SMEDDS on micelle formation. At predetermined time points of $5,10,15,30,45,60,90,120$, and 180 minutes, samples $(5 \mathrm{~mL})$ were collected and filtered through a $0.45 \mu \mathrm{m}$ membrane filter and then diluted with isopropanol. The concentration of TCG in each formulation was analyzed by HPLC.

\section{Cell study}

\section{Cell culture}

The heterogeneous human epithelial colorectal adenocarcinoma (Caco-2) cell line was purchased from Korean 
Cell Line Bank (Seoul, Republic of Korea). The cells were cultured in DMEM supplemented with 10\% FBS and 1\% penicillin/streptomycin at $37^{\circ} \mathrm{C}$ in a humidified $95 \%$ air and $5 \% \mathrm{CO}_{2}$ atmosphere.

\section{Cytotoxicity study}

Cytotoxicity studies were performed to determine the toxicity of TCG and the SMEDDS formulation. Briefly, cells in $200 \mu \mathrm{L}$ of culture medium were seeded into 96-well plates at a cell density of $5 \times 10^{4}$ cells/well. The cells were treated with the raw TCG solution as control, blank-CE, TCG-CE, blank-SM, and TCG-SM at equivalent concentrations of TCG and incubated for 24 hours at $37^{\circ} \mathrm{C}$. The samples were diluted with culture media containing $1 \%$ DMSO (v/v) to achieve various concentrations of TCG ranging from $9 \mathrm{ng} / \mathrm{mL}$ to $90 \mu \mathrm{g} / \mathrm{mL}$. After incubation for 24 hours, MTT solution $(5 \mathrm{mg} / \mathrm{mL}, 30 \mu \mathrm{L} /$ well $)$ was added to the culture medium and incubated for a further 4 hours. The medium was removed, and $200 \mu \mathrm{L}$ of DMSO was added to each well. The absorbance values of each well were measured at $560 \mathrm{~nm}$ using a microplate reader (Sunrise; Tecan Group Ltd.). The cell viability was calculated using the following equation:

$$
\text { Cell viability }(\%)=\frac{A b_{\text {test }}}{A b_{\text {control }}} \times 100
$$

where $A b_{\text {test }}$ is the absorbance value of the cells treated with samples and $A b_{\text {control }}$ is the absorbance value of the cells incubated without samples.

\section{Cellular uptake study}

We assessed the uptake of TCG into Caco-2 cells from raw TCG solution, TCG-CE, and TCG-SM. The cells were seeded in 6-well plates at $1 \times 10^{6}$ cells/well and incubated for 24 hours. The cells were treated with raw TCG solution as control, TCG-CE, and TCG-SM at an equivalent concentration of $9 \mu \mathrm{g} / \mathrm{mL}$ TCG, which was previously shown to be noncytotoxic (see method; Cytotoxicity study). After incubation for 4 hours, the medium in the wells was removed and the wells were washed three times with $1 \mathrm{~mL}$ cold phosphate-buffered saline. Cell lysis was achieved by adding $0.5 \mathrm{~mL}$ of $1 \%(\mathrm{w} / \mathrm{v})$ Triton X-100 solution to each well. Subsequently, $0.5 \mathrm{~mL}$ of acetonitrile was added to the lysed cells and shaken for 5 minutes to extract TCG from the cells. The samples were centrifuged at $15,000 \times g$ for 10 minutes. The supernatant was filtered with a $0.45 \mu \mathrm{m}$ membrane filter and analyzed by HPLC. The cellular uptake of TCG from different formulations was calculated by normalization to the amount of protein measured using the bicinchoninic acid assay.

In vitro permeability in Caco-2 cell line

The Caco- 2 cell line was used as a model system to study gastrointestinal epithelial permeability. The cells were seeded onto polycarbonate membrane (HTS Transwell-24; Corning, Cambridge, MA, USA) with a surface area of $0.33 \mathrm{~cm}^{2}$ and a diameter of $6.5 \mathrm{~mm}$ at a density of $5 \times 10^{4}$ cells/well. DMEM was used as culture medium, and cells were grown for 21 days to reach a monolayer. The wells containing cell monolayers with transepithelial electrical resistance values above $300 \Omega \cdot \mathrm{cm}^{2}$ were used for the permeability study. Raw TCG solution as control, TCG-CE, and TCG-SM at a dose equivalent to $9 \mu \mathrm{g} / \mathrm{mL}$ of TCG was prepared by diluting with Hanks' balanced salt solution (HBSS, pH 7.4). Permeability studies were performed to assess apical-basolateral (A-B) transport and basolateral-apical (B-A) transport. The Caco-2 cell monolayer was washed with prewarmed HBSS before the permeability study. To measure A-B transport, $250 \mu \mathrm{L}$ of the test solution was added to the apical chamber and $800 \mu \mathrm{L}$ HBSS to the basolateral chamber. To measure B-A transport, $800 \mu \mathrm{L}$ of test solution was added to the basolateral chamber and $250 \mu \mathrm{L}$ HBSS to the apical chamber. Samples of $70 \mu \mathrm{L}$ were then taken from the apical or basolateral chamber at predetermined time intervals $(30,60,120$, and 180 minutes) and immediately replaced with the same volume of HBSS. The TCG concentration in the buffer was determined by liquid chromatography with tandem time-of-flight mass spectroscopy (LCTOF MS/MS) analysis (see method; LC-TOF MS/MS analysis of TCG). The apparent permeability $\left(\mathrm{P}_{\text {app }}\right)$ across the Caco-2 cell monolayer was calculated using the following equation:

$$
\mathrm{P}_{\text {app }}=\frac{\Delta \mathrm{C} / \Delta \mathrm{t}}{\text { Area } \times 60 \times \mathrm{C}_{0}}
$$

where $\mathrm{P}_{\text {app }}$ is the apparent permeability coefficient $(\mathrm{cm} / \mathrm{s})$, $\Delta \mathrm{C} / \Delta \mathrm{t}$ is the rate of drug appearance in the receiving chamber $(\mathrm{nmol} / \mathrm{s})$, Area is the surface area of the Transwell membrane $\left(0.33 \mathrm{~cm}^{2}\right)$, and $\mathrm{C}_{0}$ is the initial concentration of transported TCG $(\mu \mathrm{M})$. The efflux ratio (ER) was then calculated using the equation:

$$
\text { Efflux ratio }(\mathrm{ER})=\frac{\mathrm{P}_{\text {app }}(B-A)}{\mathrm{P}_{\text {app }}(A-B)}
$$

to determine the ratio of $\mathrm{B}-\mathrm{A}$ transport $\left(\mathrm{P}_{\text {app }}(B-A)\right)$ to $\mathrm{A}-\mathrm{B}$ transport $\left(\mathrm{P}_{\text {app }}(A-B)\right)$. 


\section{Pharmacokinetic studies}

\section{Evaluation of in vivo oral bioavailability}

All animal experiments were conducted in accordance with the "Guiding Principles in the Use of Animals in Toxicology" adopted by the Society of Toxicology (Reston, VA, USA), and the experimental protocols were approved by Chungnam National University Institutional Animal Care Committee (Protocol no CNU-00911, Daejeon, Republic of Korea). Male Sprague Dawley rats aged 6-7 weeks with a body weight of 200-250 g were obtained from Samtaco Bio Korea Inc. (Osan, Republic of Korea) and housed at $22^{\circ} \mathrm{C}$ in a dark-light cycle of 12 hours where food and water could be freely accessed. Animals were adapted for 2 weeks before starting the study. The rats were randomly divided into three groups of eleven rats. The raw TCG suspension as control, TCG-CE, and TCG$\mathrm{SM}$ at an equivalent dose of TCG was orally administered to rats at a dose of $10 \mathrm{~mL} / \mathrm{kg}$. The raw TCG suspension was prepared by suspending TCG in $0.5 \%(\mathrm{w} / \mathrm{v})$ carboxymethylcellulose solution with low viscosity. The TCG-CE and TCG-SM were diluted with distilled water. Approximately $0.3 \mathrm{~mL}$ of blood samples was collected from the retro-orbital plexus using heparinized tubes at $0,0.17,0.33,0.66,1.0,1.5$, $2,4,6,8,12$, and 24 hours and centrifuged immediately at $17,000 \times g$ for 15 minutes at $4^{\circ} \mathrm{C}$. The plasma samples were kept frozen at $-80^{\circ} \mathrm{C}$ until LC-TOF MS/MS analysis.

\section{LC-TOF MS/MS analysis of TCG}

The concentrations of TCG were determined using an LCTOF MS/MS system consisting of two Shimadzu LC-20AD pumps, a Shimadzu CBM-20A HPLC pump controller (Shimadzu Corp., Kyoto, Japan), a CTC HTS PAL autosampler (CEAP Technologies, Carrboro, NC, USA) and a quadrupole time-of-flight TripleTOFTM 5600 mass spectrometer (SCIEX, Foster City, CA, USA). The chromatographic column used for this assay was a Kinetex ${ }^{\circledR}$ XB-C18 column (50×2.1 mm, $2.6 \mu \mathrm{m}$; Phenomenex, Torrance, CA, USA). The mobile phase for TCG consisted of solvent A $(0.1 \%$ formic acid in distilled water) and solvent $\mathrm{B}(0.1 \%$ formic acid in acetonitrile), with a gradient elution (0-0.5 minute, $10 \%$ solvent $\mathrm{B}$; $0.5-1.0$ minute, $10 \%-95 \%$ solvent $\mathrm{B}$; $1.0-1.5$ minutes, $95 \%$ solvent $B$; $1.5-1.6$ minutes, $95 \%-10 \%$ solvent $\mathrm{B}$; $1.6-3.0$ minutes, $10 \%$ solvent $\mathrm{B}$ ). The flow rate was $0.4 \mathrm{~mL} / \mathrm{min}$, and the injection volume was $10 \mu \mathrm{L}$. The scan mass spectra of TOF MS/MS and TOF MS were recorded using the positive ion mode. To analyze TCG and an internal standard (ISTD, verapamil), m/z 100-600 with 0.15 second accumulation time was used for TOF MS/MS. For quantification, the TCG and ISTD (m/z 523.1 and 455.3) and their respective product ions (m/z 153.0 and 165.1) were selected for quantitative analysis. The temperature of ion source was set at $500^{\circ} \mathrm{C}$ with a curtain gas flow of $33 \mathrm{~L} / \mathrm{min}$ and $4.5 \mathrm{kV}$ of the ion spray. For TCG and ISTD, the declustering potentials were 100 and $125 \mathrm{~V}$ and the collision energies were 40 and $30 \mathrm{~V}$, respectively. The calibration curves for TCG was prepared at concentrations of 3-2,200 ng/mL and showed a good linearity with an $R^{2}$ value $>0.99$.

\section{Pharmacokinetic data analysis}

WinNonlin software (8.0; Pharsight Co., Sunnyvale, CA, USA) was used to perform noncompartmental analysis. The maximum plasma concentration $\left(\mathrm{C}_{\max }\right)$, the time to reach the maximum plasma concentration $\left(\mathrm{T}_{\max }\right)$, and the half-life $\left(\mathrm{T}_{1 / 2}\right)$ were observed from the plasma concentration-time profiles. The area under the concentration-time curve $\left(\mathrm{AUC}_{0-\infty}\right)$ was calculated by the linear trapezoidal method. The relative bioavailability (RBA) was calculated using the following equation:

$$
\mathrm{RBA}(\%)=100 \times \frac{\mathrm{AUC}_{0-\infty}(\text { test })}{\mathrm{AUC}_{0-\infty}(\text { control })}
$$

where $\mathrm{AUC}_{0-\infty}$ (test) was the $\mathrm{AUC}_{0-\infty}$ of TCG-CE or TCG$\mathrm{SM}$, and $\mathrm{AUC}_{0-\infty}$ (control) was the $\mathrm{AUC}_{0-\infty}$ of raw TCG suspension.

\section{Pharmacodynamic study}

Preparation of platelet-rich plasma (PRP) and platelet-poor plasma (PPP)

Light transmission aggregometry (LTA) was used to evaluate the antiplatelet activities of TCG. PRP and PPP were prepared prior to the experiment. Rat blood was collected via the jugular vein or postorbital plexus and drawn into a tube containing $3.2 \%$ sodium citrate solution ( $1 / 9 \mathrm{vol}$ of blood). The blood was centrifuged at $200 \times g$ at room temperature for 15 minutes to obtain PRP. The remaining blood was centrifuged at $2,000 \times g$ at room temperature for 10 minutes to obtain PPP.

\section{Antiplatelet activity test}

The in vitro and ex vivo antiplatelet activities of raw TCG suspension as control and TCG-SM were evaluated using an automated aggregometer (Chrono-Log Model 700, ChronoLog Corporation, Havertown, PA, USA). The platelet number of PRP was measured using a hematology analyzer (Advia 2120i; Siemens Healthineers, Forchheim, Germany) and adjusted to $5 \times 10^{7}$ platelets $/ \mathrm{mL}$ against a PPP blank.

For in vitro studies, rat blood for preparation of PRP was collected via the jugular vein under anesthesia with pentobarbital (50 mg/kg, intraperitoneal injection). The obtained 
PRP was incubated with the raw TCG suspension or TCG-SM for 30 minutes at room temperature before aggregation was induced. Then, $240 \mu \mathrm{L}$ PRP was stirred and incubated for 1 minute at $37^{\circ} \mathrm{C}$ before $10 \mu \mathrm{L}$ ADP $(20 \mu \mathrm{M})$ was added to induce platelet aggregation. Platelet aggregation was measured 10 minutes after addition of ADP.

For ex vivo studies, rats were randomly assigned to two treatment groups $(n=9)$. Blood was collected from the jugular vein or postorbital plexus at 1,2, 5, 10, and 24 hours after a single oral administration of raw TCG suspension or TCG-SM at an equivalent dose of TCG $(2,5$, and $10 \mathrm{mg} / \mathrm{kg})$. Approximately $1.8 \mathrm{~mL}$ blood samples were collected into a tube containing $0.2 \mathrm{~mL} 3.2 \%$ sodium citrate solution ( $\mathrm{pH}$ 7.4). The blood was centrifuged $(200 \times g$ for 15 minutes at room temperature) to obtain PRP. After obtaining PRP, the remaining blood was centrifuged $(2,000 \times g$ for 10 minutes at room temperature) to obtain PPP. Then, the antiplatelet activities of raw TCG suspension and TCG-SM were evaluated as described above.

\section{Pharmacodynamic data analysis}

The values for in vitro $50 \%$ effective concentration $\left(\mathrm{EC}_{50}\right)$ were calculated from nonlinear regression for the log concentration-response relationship for inhibition of platelet aggregation. To evaluate the ex vivo antiplatelet activity, the values of the AUC were calculated from the aggregometer and were used to calculate the percentage inhibition of platelet aggregation (IPA\%) using the following equation:

$$
\text { IPA } \%=1-\frac{\text { AUC of sample }}{\text { AUC of blank }} \times 100
$$

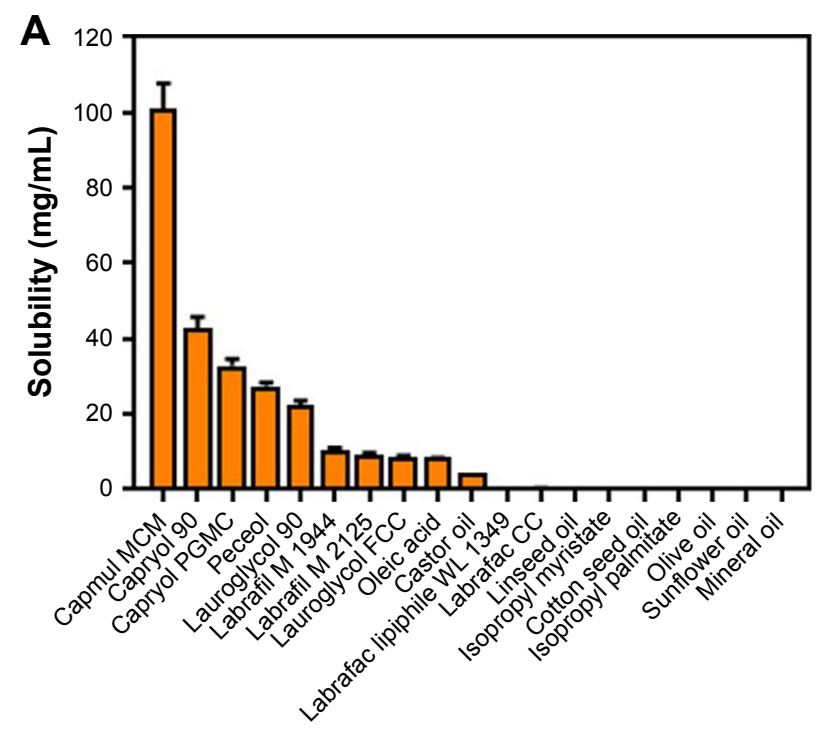

where the AUC of sample and AUC of blank were the AUC of sample PRP and blank PPP, respectively. The IPA\% values of samples at predicted time-points were normalized to that of PRP at 0 hour. The values for the ex vivo $50 \%$ effective dose $\left(\mathrm{ED}_{50}\right)$ were calculated from the linear regression for log dose-response (95\% CI of X when $\mathrm{Y}=50$ ). The area under the inhibitory curves $\left(\mathrm{AUIC}_{0-24}\right)$ was calculated from the response-time relationship. GraphPad Prism 7 (GraphPad Software Inc., La Jolla, CA, USA) was used to calculate the $\mathrm{EC}_{50}, \mathrm{ED}_{50}$, and $\mathrm{AUIC}_{0-24}$ values.

\section{Statistical analysis}

Data are expressed as mean $\pm \mathrm{SD}$, except for the antiplatelet activity results, which are presented as mean \pm standard error of the mean (SEM). Student's $t$-test was used to assess the significance of differences. For the pharmacokinetic studies, one-way ANOVA was used and performed using Prism 7 (GraphPad Software Inc.). Statistical significance was defined as $P<0.05$.

\section{Results and discussion Preparation and characterization of optimized TCG-SM}

\section{Screening of excipients for TCG-SM}

To develop a SMEDDS to dissolve the unit dose of TCG (90 mg) using a minimum volume of formulation, the first step was to select the appropriate excipients to achieve high solubility of TCG. The solubility of TCG for several excipients was shown in Figure 1. As shown in Figure 1A, Capmul MCM produced significantly higher solubility $(101.19 \mathrm{mg} / \mathrm{mL})$ than other oils $(0.03-42.97 \mathrm{mg} / \mathrm{mL})$. The solubility of TCG

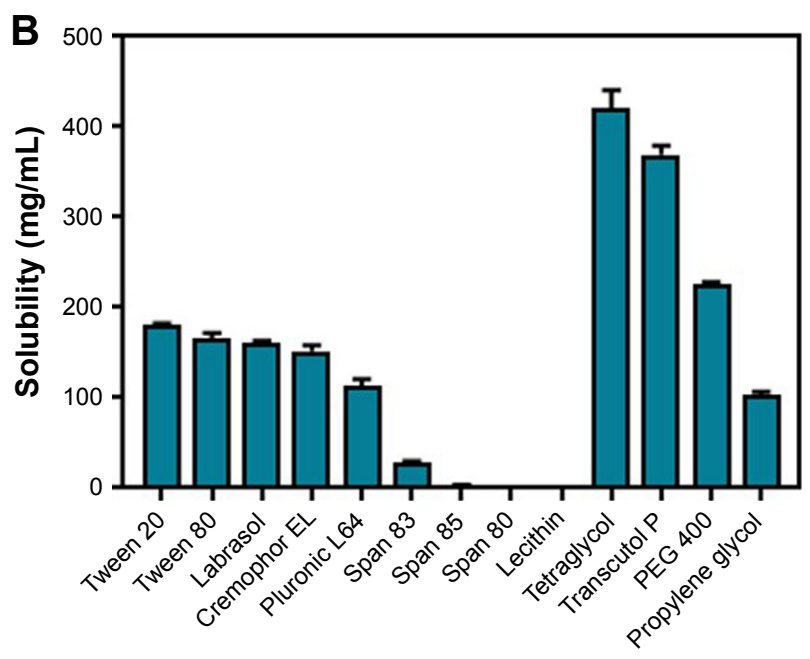

Figure I Solubility of ticagrelor in various excipients.

Notes: (A) Oils. (B) Surfactants and cosurfactants. Values are expressed as mean $\pm S D(n=3)$. 
in the oil components of SMEDDS is crucial because oils are liable to solubilize hydrophobic drugs and can further improve the lipophilicity of the dissolved drug. ${ }^{25}$ Therefore, Capmul MCM with the highest solubility was used as the oil of the SMEDDS formulation. Of the screened surfactants, Tween 20, Tween 80, Labrasol, Cremophor EL, and Pluronic L64 all provided good solubility for TCG $(>110 \mathrm{mg} / \mathrm{mL})$. Generally, surfactants lower the surface energy and allow the oil to disperse into small droplet sizes in the aqueous phase. ${ }^{26}$ Among the cosurfactants screened, tetraglycol and Transcutol P produced the highest solubility for TCG (420.34 and $369.51 \mathrm{mg} / \mathrm{mL}$, respectively) (Figure 1B). Cosurfactants can help increase the solubility of the drug in micelles, form micelles with the surfactant in the aqueous phase, prevent drug precipitation, and maintain a more stable micelle. ${ }^{27}$

The droplet size, transmittance, and phase separation were evaluated to confirm the self-emulsifying ability of the preselected surfactants and cosurfactants. They were graded as shown in Table S1 (supplementary materials). The results of emulsification studies related to various combinations of surfactants and cosurfactants were listed in Table 2. Compared with other surfactants, Cremophor EL exhibited grade A emulsifying ability and showed no phase separation. Tween 20 exhibited excellent emulsifying ability (grade A or B) and showed no phase separation in distilled water and pH 6.8 media. Although Tween 20 showed phase separation in $\mathrm{pH} 1.2$ and $\mathrm{pH} 4.0$ media, an emulsion was formed when the samples were remixed. For the cosurfactants, the emulsifying ability of Transcutol $\mathrm{P}$ was higher than that of tetraglycol, especially in combination with Cremophor EL or Tween 20. Based on the above results, small droplet size $(<300 \mathrm{~nm})$, high transmittance ( $>90 \%$, grades A and B), and a lack of phase separation were observed in SMEDDS formulations that combined Tween 20 or Cremophor EL as surfactant, Transcutol P as cosurfactant, and Capmul MCM as oil.

Next, pseudoternary phase diagrams were prepared for both surfactants to determine the final components and set the range to be used in the experiments. In Figure 2A and $\mathrm{B}$, the green line represents a microemulsion with a clear and/or transparent appearance (grade A), the red line represents microemulsions with a slightly less clear appearance (grade B), and the blue line indicates grade C emulsions with a bluish-white appearance. The grade A and B regions of SMEDDS formulations including Cremophor EL as surfactant were wider than those for SMEDDS formulation using Tween 20 as surfactant. This indicated that SMEDDS formulations including Cremophor EL as surfactant had better self-microemulsification properties than those containing Tween 20. A small droplet size results in an increased interfacial surface area, which reduces the micelle surface energy, enables faster drug release, and improves drug absorption. ${ }^{28}$ Thus, the final composition selected for SMEDDS was a combination of Capmul MCM/Cremophor EL/Transcutol P. When the concentration of oil exceeded $40 \%$, unstable emulsions were formed, and it was verified that the droplet size increased as the oil content increased. In addition, the SMEDDS formulation could form droplets of $<300 \mathrm{~nm}$ when the surfactant and cosurfactant were present in the mixture in the range of $10 \%-80 \%$. Therefore,

Table 2 Evaluation of emulsification and phase separation according to the combination of preselected excipients

\begin{tabular}{|c|c|c|c|c|c|c|c|c|c|c|}
\hline \multicolumn{3}{|c|}{$2: 4: 4$ (w/w \%) } & \multicolumn{8}{|c|}{ Dilution media } \\
\hline \multirow[t]{2}{*}{ Oil } & \multirow[t]{2}{*}{ Surfactant } & \multirow[t]{2}{*}{ Cosurfactant } & \multicolumn{2}{|l|}{ Water } & \multicolumn{2}{|l|}{ pH 1.2} & \multicolumn{2}{|l|}{ pH 4.0} & \multicolumn{2}{|l|}{ pH 6.8} \\
\hline & & & Grade $^{a}$ & $\begin{array}{l}\text { Phase } \\
\text { separation }^{\mathrm{b}}\end{array}$ & Grade & $\begin{array}{l}\text { Phase } \\
\text { separation }\end{array}$ & Grade & $\begin{array}{l}\text { Phase } \\
\text { separation }\end{array}$ & Grade & $\begin{array}{l}\text { Phase } \\
\text { separation }\end{array}$ \\
\hline \multirow{10}{*}{$\begin{array}{l}\text { Capmul } \\
\text { MCM }\end{array}$} & \multirow[t]{2}{*}{ Labrasol } & Transcutol P & $\mathrm{D}$ & 0 & $C$ & 0 & $C$ & 0 & $C$ & 0 \\
\hline & & Tetraglycol & C & 0 & $C$ & 0 & C & O & $C$ & 0 \\
\hline & \multirow[t]{2}{*}{ Pluronic L64 } & Transcutol P & $\mathrm{C}$ & 0 & $C$ & 0 & $D$ & 0 & C & 0 \\
\hline & & Tetraglycol & $C$ & $x$ & $C$ & 0 & $C$ & 0 & $C$ & 0 \\
\hline & \multirow[t]{2}{*}{ Tween 80} & Transcutol P & $A$ & $x$ & $B$ & 0 & $B$ & $\Delta$ & $B$ & 0 \\
\hline & & Tetraglycol & B & $x$ & B & O & B & $\Delta$ & B & 0 \\
\hline & \multirow[t]{2}{*}{ Tween 20} & Transcutol P & $A$ & $x$ & $A$ & $\Delta$ & $A$ & $\Delta$ & B & $x$ \\
\hline & & Tetraglycol & B & $x$ & $B$ & $\Delta$ & $A$ & $\Delta$ & B & $x$ \\
\hline & \multirow[t]{2}{*}{ Cremophor EL } & Transcutol P & $A$ & $x$ & $A$ & $x$ & $A$ & $x$ & $A$ & $x$ \\
\hline & & Tetraglycol & $A$ & $x$ & $A$ & $x$ & $A$ & $x$ & $A$ & $x$ \\
\hline
\end{tabular}

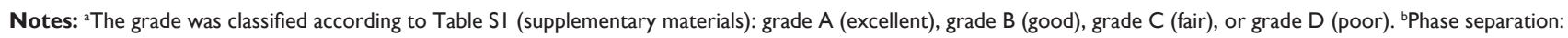
$O$ (phase separation occurred; emulsion did not form when remixed), $\Delta$ (phase separation occurred; when remixed, emulsion was formed), $X$ (no phase separation occurred). 
A

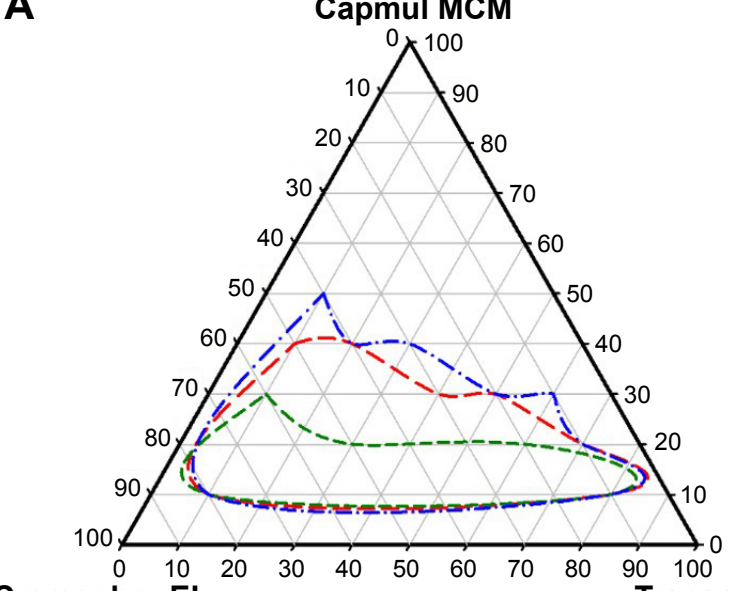

Cremophor EL

B

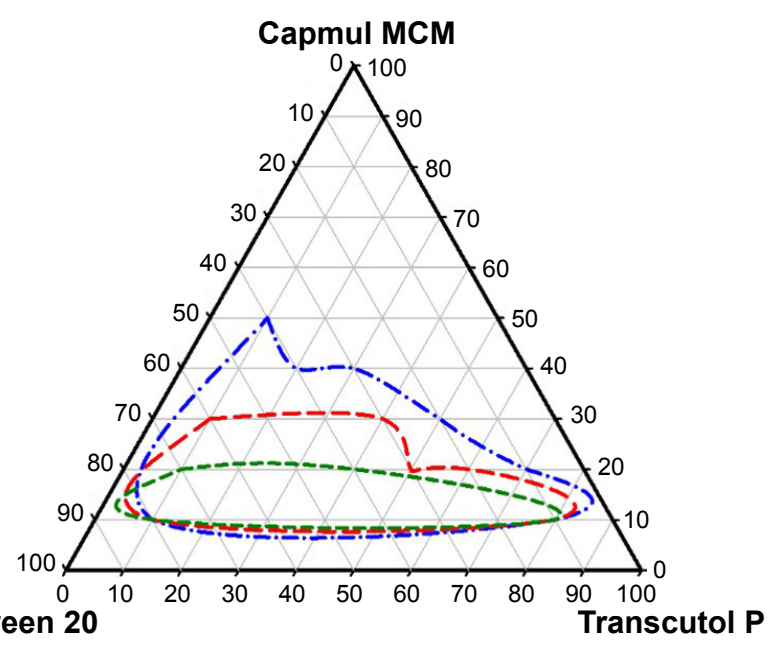

$$
\text { - -. Grade A } \cdots \text { Grade B } \cdots \text { Grade C }
$$

Figure 2 Pseudoternary phase diagram.

Notes: (A) Capmul MCM, Cremophor EL, and Transcutol P. (B) Capmul MCM, Tween 20, and Transcutol P. Green line, red line, and blue line indicate compositions forming microemulsion of the grade $A$, grade $B$, and grade $C$, respectively.

SMEDDS formulations were developed with composition of $10 \%-40 \%$ oil and $10 \%-80 \%$ surfactant/cosurfactant to produce transparent and homogeneous microemulsions (grade A, B) and to avoid the range in which unstable microemulsions were formed.

\section{Design of experiments for optimizing TCG-SM}

Scheffe's mixture design was applied to optimize the TCG$\mathrm{SM}$. The results of responses were fitted to Design-Expert 11 software and statistical analysis suggested different fitting models and their relationship to the variables. The solubility of TCG in SMEDDS $\left(\mathrm{Y}_{1}\right)$, precipitation $\left(\mathrm{Y}_{2}\right)$, droplet size $\left(\mathrm{Y}_{3}\right)$, and transmittance $\left(\mathrm{Y}_{4}\right)$ were important variables in the preparation of SMEDDS that maintained a stable formulation and improved the oral absorption of insoluble drugs. A high solubility of TCG in SMEDDS allows the SMEDDS to include a high drug content in a minimum volume of a stable formulation without precipitation. When the SMEDDS formulation is dispersed in an aqueous phase, some of the drugs are not encapsulated in micelles and are present as free drug, which can lead to precipitation. ${ }^{29}$ Therefore, the relationship between precipitation and variables was confirmed. A small droplet size increases the surface area of micelles, which enhances drug absorption by intestinal membrane contact and enables rapid drug dissolution. ${ }^{30}$ Transmittance was chosen to monitor the goal of forming a clear homogeneous microemulsion when dispersed in an aqueous phase.

As shown in Table 3, the statistical models of $\mathrm{Y}_{1}, \mathrm{Y}_{2}, \mathrm{Y}_{3}$, and $\mathrm{Y}_{4}$ responses were fitted to linear, quadratic, cubic, and special quadratic models, respectively. Various statistical parameters for each model such as sequential $P$-value, lack of fit, $R^{2}$, and adjusted $R^{2}$ value were considered when fitting the statistical models. The sequential $P$-values of all suggested models were $<0.05$, which indicated that the model parameters were significant at the $95 \%$ confidence level. ${ }^{31}$ The lack-of-fit $P$-values of the models were $>0.05$, suggesting that the fitted model was appropriate. ${ }^{32}$ The $R^{2}$ and adjusted $R^{2}$ were analyzed to determine how much the variability of

Table 3 Summary of model fitting and statistical analysis

\begin{tabular}{|l|l|l|l|l|l|l|}
\hline Responses & $\begin{array}{l}\text { Suggested } \\
\text { model }\end{array}$ & Model $\boldsymbol{P}$-value & $\begin{array}{l}\text { Lack-of-fit } \\
\boldsymbol{P} \text {-value }\end{array}$ & $\boldsymbol{R}^{2}$ & Adjusted $\boldsymbol{R}^{2}$ & $\begin{array}{l}\text { Adequate } \\
\text { precision }\end{array}$ \\
\hline$Y_{1}:$ Solubility & Linear & $<0.000 \mathrm{I}$ & 0.7558 & 0.9646 & 0.9596 & 37.7012 \\
\hline$Y_{2}:$ Precipitation & Quadratic & 0.0432 & 0.4149 & 0.7732 & 0.6701 & 8.0892 \\
\hline$Y_{3}:$ Droplet size & Cubic & 0.0018 & 0.2559 & 0.9882 & 0.9731 & 23.3584 \\
\hline$Y_{4}:$ Transmittance & Special quartic & 0.0022 & 0.0606 & 0.9879 & 0.9757 & 23.4122 \\
\hline
\end{tabular}

Note: $R^{2}$, squared correlation coefficient. 
experimental data was reflected by the models. ${ }^{33} \mathrm{All} R^{2}$ and adjusted $R^{2}$ values for $\mathrm{Y}_{1}, \mathrm{Y}_{3}$, and $\mathrm{Y}_{4}$ were $>0.9$, indicating that the data were close to the fitted values. ${ }^{34}$ Although the $R^{2}$ value of $\mathrm{Y}_{2}$ was 0.7732 , the precision of $\mathrm{Y}_{2}$ was adequate at 8.0892, which indicates that the $\mathrm{Y}_{2}$ model could be used to navigate the design space (adequate precision $>4$ ) ${ }^{35}$ All $R^{2}$ and adjusted $R^{2}$ values of responses were similar (difference between $R^{2}$ and adjusted $R^{2}<0.2$ ). A similar value for $R^{2}$ and adjusted $R^{2}$ has been reported to be an appropriate goodness-of-fit indicator. ${ }^{36}$

The relationship between the factors was schematically illustrated in three-dimensional response surface plots and coefficient equations (Figure 3 and Table S2, supplementary materials). As shown in Figure 3 and Table S3 (supplementary materials), the solubility of TCG in SMEDDS ( $\left.\mathrm{Y}_{1}\right)$ ranged from 126.51 to $330.59 \mathrm{mg} / \mathrm{mL}$ and the precipitation of TCG $\left(\mathrm{Y}_{2}\right)$ ranged from $0.2 \%$ to $67.7 \%$ (Figure $3 \mathrm{~A}$ and $\mathrm{B}$ ).

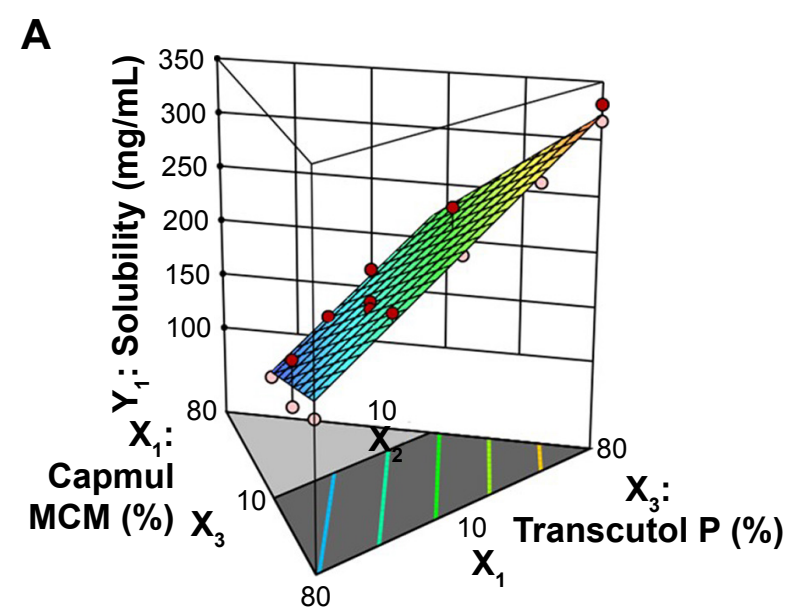

$\mathrm{X}_{2}$ : Cremophor EL (\%)

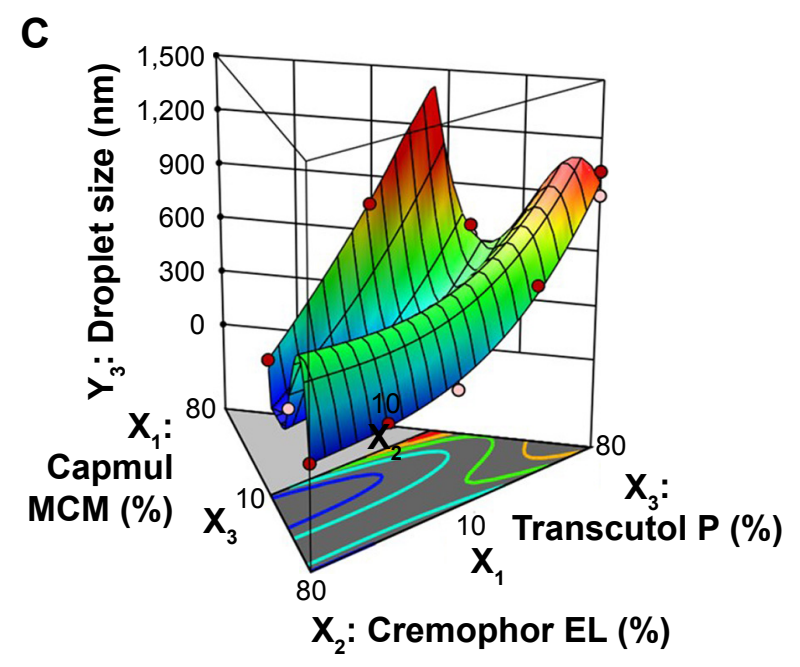

For droplet size $\left(\mathrm{Y}_{3}\right)$ and transmittance $\left(\mathrm{Y}_{4}\right)$, the ranges of $\mathrm{Y}_{3}$ and $\mathrm{Y}_{4}$ were from 54.7 to $1,023.6 \mathrm{~nm}$ and $49.5 \%$ to $99.2 \%$, respectively (Figure $3 \mathrm{C}$ and $\mathrm{D}$ ). The solubility of TCG in SMEDDS $\left(\mathrm{Y}_{1}\right)$ and precipitation $\left(\mathrm{Y}_{2}\right)$ increased as $\mathrm{X}_{3}$ increased. There was no significant interaction effect between $\mathrm{X}_{1}, \mathrm{X}_{2}$, and $\mathrm{X}_{3}$ in the solubility of TCG. In the case of droplet size $\left(\mathrm{Y}_{3}\right)$, the effect of the interaction between $\mathrm{X}_{2}$ and $X_{3}$ was significant, and the $Y_{3}$ value tended to decrease as $X_{2}$ increased and $X_{3}$ decreased. The transmittance $\left(Y_{4}\right)$ was influenced by the interaction of $\mathrm{X}_{2}$ and $\mathrm{X}_{3}$ except for the main effect, and the value of $\mathrm{Y}_{4}$ tended to increase as $\mathrm{X}_{2}$ increased and $\mathrm{X}_{3}$ decreased.

The factors were optimized using the desirability function by considering all the responses. The goals of $Y_{1}$ and $Y_{4}$ were set to be maximized and those of $Y_{2}$ and $Y_{3}$ were set to be minimized. Figure 4A shows the desirability plot that reflected the effect of the different variables on the four

B

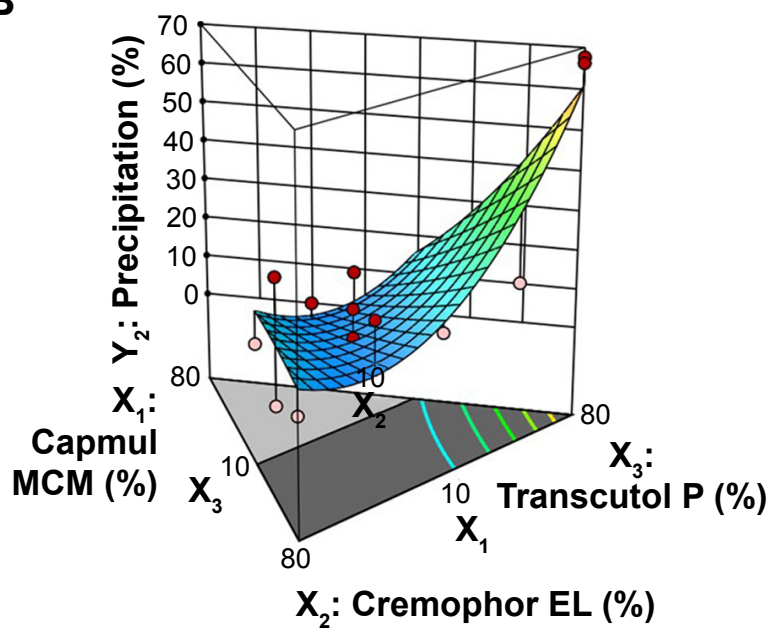

D

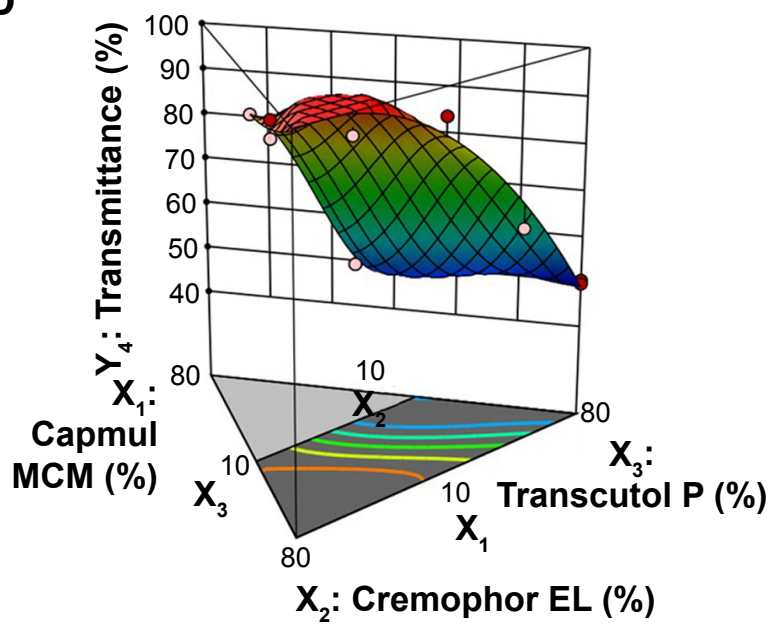

Figure 3 Three-dimensional surface plots of responses.

Notes: (A) $Y_{1}$ : Solubility of TCG in SMEDDS. (B) $Y_{2}$ : Precipitation. (C) $Y_{3}$ : Droplet size. (D) $Y_{4}$ : Transmittance. 
A

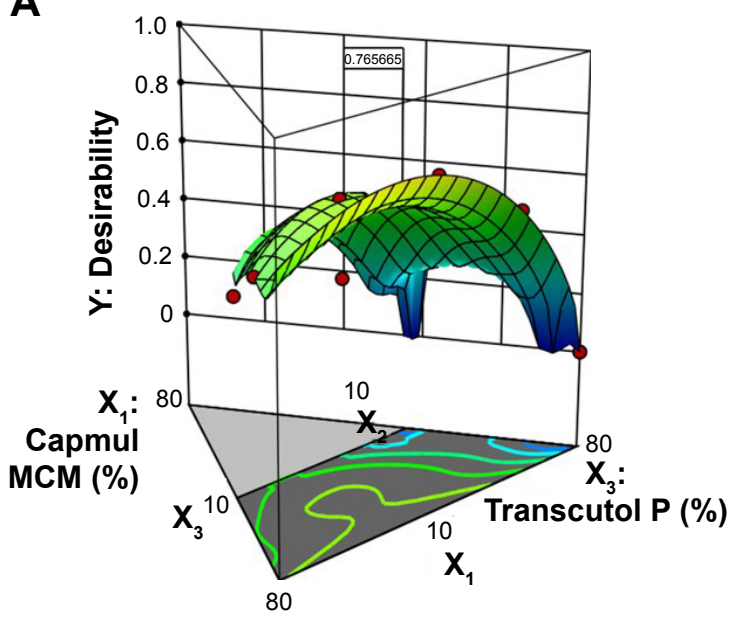

B

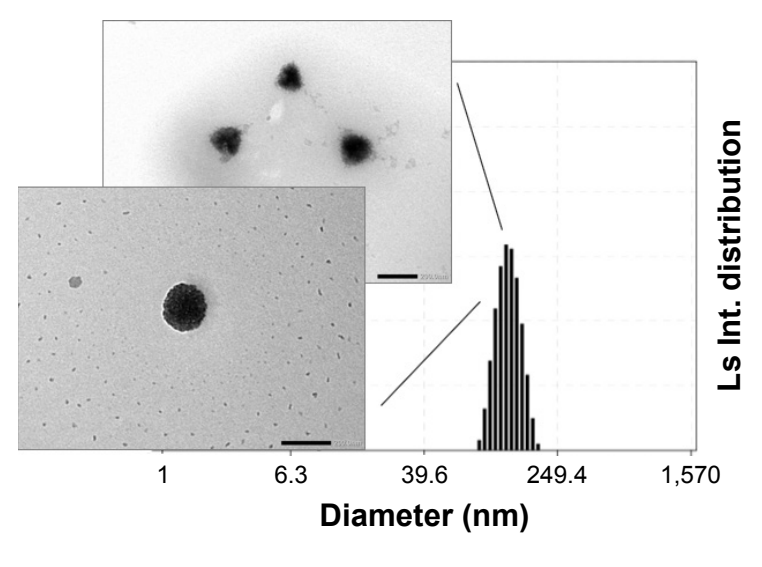

Figure 4 (A) Desirability plot using numerical optimization. (B) Transmission electron microscopy images and an electrophoretic laser scattering measurement of optimized ticagrelor-loaded self-microemulsifying drug delivery system in corresponding distilled water. Scale bar $200 \mathrm{~nm}$.

responses. The optimized values of $\mathrm{X}_{1}, \mathrm{X}_{2}$, and $\mathrm{X}_{3}$ were $10.0 \%, 53.8 \%$, and $36.2 \%$, respectively. The desirability value of the corresponding point was 0.766 . The optimized factors and the values of predicted responses are listed in Table 4. To confirm the prediction accuracy, the difference between the predicted and actual values for each response was calculated as a percentage. Although the percentage error associated with $Y_{1}(6.25 \%)$ and $Y_{3}(5.61 \%)$ was slightly high, the errors between predicted values and actual values for $\mathrm{Y}_{2}(2.50 \%)$ and $\mathrm{Y}_{4}(1.36 \%)$ were very low. The fact that the errors were $<10 \%$ indicated that the optimization of TCG-SM was successful.

The transmission electron microscopy data of optimized TCG-SM showed that the microemulsion with spherical droplet shapes in the nanometer range were observed and of a size similar to that obtained by ELS measurement $(116.4 \pm 5.7 \mathrm{~nm})$, as shown in Figure 4B.

It has been reported that self-forming microemulsions exhibit enhanced dissolution patterns. ${ }^{37,38}$ In this study, we assumed that the dissolution rates of TCG were significantly improved by the optimized TCG-SM formulation. For that reason, the dissolution profiles of Brilinta as control (commercial product), TCG-CE, and TCG-SM were determined in the media at $\mathrm{pH} 1.2, \mathrm{pH} 4.0$, and $\mathrm{pH} 6.8$ and in distilled water (Figure 5). During the 3-hour experimental period, Brilinta showed very low dissolution of $<10 \%$ in all media. The TCG-CE formulation slightly increased the dissolution of TCG within 3 hours in all media, with $>40 \%$ dissolution in $\mathrm{pH} 1.2$ media, $\mathrm{pH} 4.0$ media, and distilled water $(46.3 \%, 41.3 \%$, and $43.1 \%$, respectively), but not pH 6.8 media (34.6\%). The optimized TCG-SM significantly enhanced the dissolution of TCG within 30 minutes in all media, with $>85 \%$ dissolution $(89.4 \%, 90.8 \%, 86.5 \%$, and $97.1 \%$ in $\mathrm{pH} 1.2, \mathrm{pH} 4.0, \mathrm{pH} 6.8$ media, and distilled water, respectively).

The SMEDDS formulation exhibited an excellent solvent capacity for hydrophobic drugs and formed a selfmicroemulsion after the penetration of water. ${ }^{39}$ The oil in

Table 4 Predicted values and actual values of optimized TCG-SM

\begin{tabular}{|l|l|l|l|l|l|l|l|l|}
\hline $\begin{array}{l}\text { Optimized } \\
\text { factors }\end{array}$ & Response & Goal & Importance & $\begin{array}{l}\text { 95\% Cl low } \\
\text { predicted } \\
\text { value }\end{array}$ & $\begin{array}{l}\text { Predicted } \\
\text { value }\end{array}$ & $\begin{array}{l}\text { 95\% Cl high } \\
\text { predicted } \\
\text { value }\end{array}$ & $\begin{array}{l}\text { Actual } \\
\text { value }\end{array}$ & $\begin{array}{l}\text { Error } \\
\text { percentage (\%) }\end{array}$ \\
\hline $\begin{array}{l}\mathrm{X}_{1}: 10.0 \% \\
\mathrm{X}_{2}: 53.8 \% \\
\mathrm{X}_{3}: 36.2 \%\end{array}$ & $\mathrm{Y}_{1}:$ Solubility $(\mathrm{mg} / \mathrm{mL})$ & Maximize & +++ & $212.0 \mathrm{I}$ & 222.32 & 232.62 & $236.2 \pm 3.6$ & 6.25 \\
\cline { 2 - 9 } & $\mathrm{Y}_{2}:$ Precipitation $(\%)$ & Minimize & +++ & -4.0 & 10.4 & 24.7 & $10.6 \pm 0.3$ & 2.50 \\
\cline { 2 - 9 } & $\mathrm{Y}_{3}:$ Droplet size $(\mathrm{nm})$ & Minimize & +++ & 25.6 & 116.7 & 207.8 & $110.2 \pm 2.6$ & 5.61 \\
\cline { 2 - 9 } & $\mathrm{Y}_{4}:$ Transmittance $(\%)$ & Maximize & +++ & 90.7 & 95.3 & 99.8 & $96.6 \pm 0.2$ & 1.36 \\
\hline
\end{tabular}

Note: Values are expressed as mean \pm SD $(n=3)$.

Abbreviations: TCG-SM, ticagrelor-loaded self-microemulsifying drug delivery system; $\mathrm{Cl}$, confdence interval. 

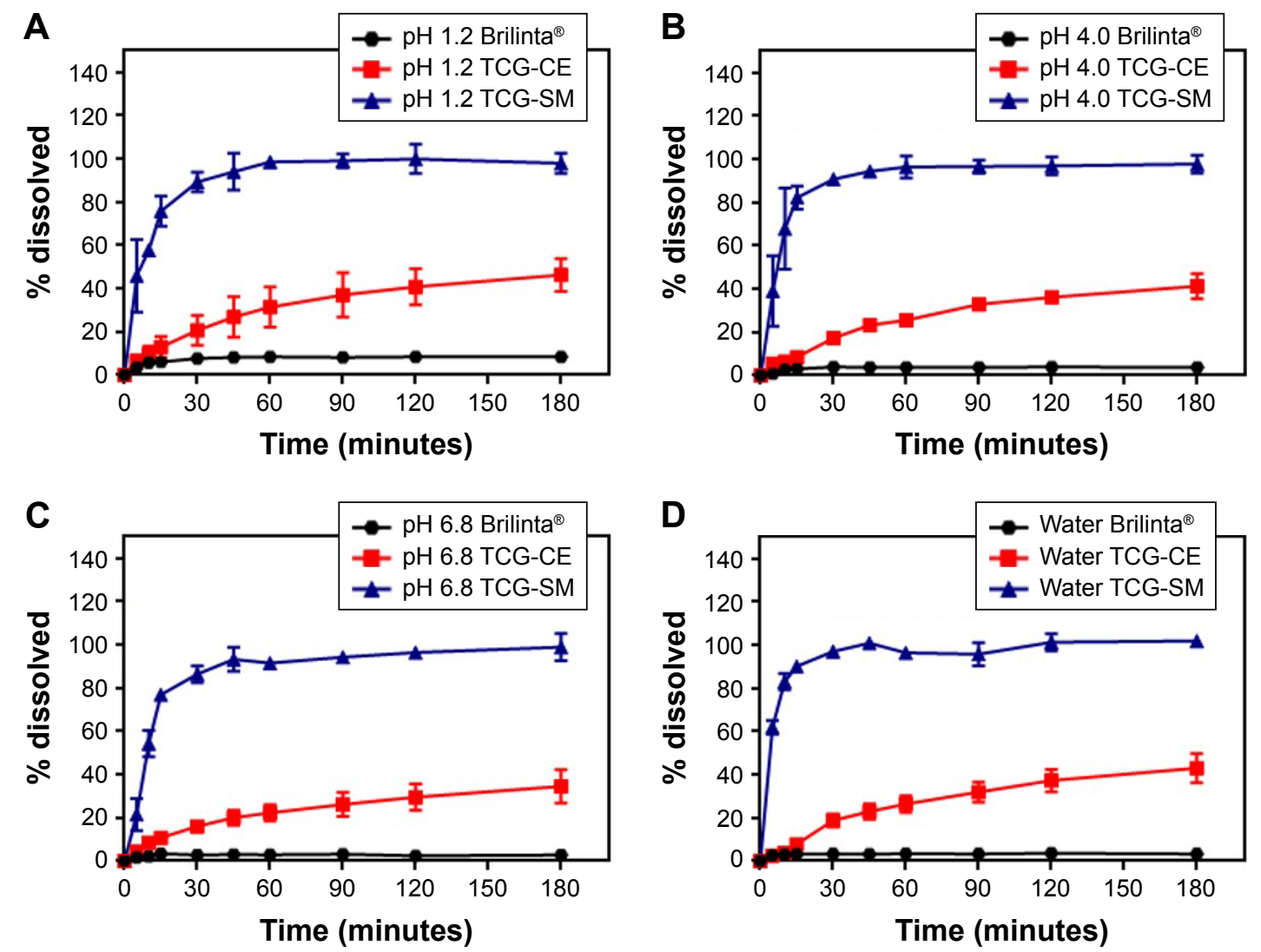

Figure 5 Dissolution profile of Brilinta ${ }^{\circledR}$, TCG-CE, and TCG-SM in $(\mathbf{A}) \mathrm{pH} 1.2$ media, (B) pH 4.0 media, (C) pH 6.8 media, and (D) distilled water. Notes: Values are expressed as mean $\pm S D(n=3)$.

Abbreviations: TCG-SM, ticagrelor-loaded self-microemulsifying drug delivery system; TCG-CE, ticagrelor-loaded Cremophor EL.

the SMEDDS can improve the emulsification ability and improve the interfacial fluidity of surfactants in micelles when the formulation is diluted with aqueous medium in the presence of surfactants with a high hydrophilic-lipophilic balance. ${ }^{40}$ These results demonstrated that TCG-SM showed a higher dissolution than TCG-CE, which did not form oil-dispersed micelles because it contained only surfactant. These characteristics of the optimized TCG-SM indicate that the formulation not only provides a large surface area by forming nano-sized droplets but also improves the solubility and dissolution of TCG.

\section{Cell study}

\section{In vitro cytotoxicity study}

The cytotoxicity of the raw TCG solution, blank-CE, blank-SM, TCG-CE, and TCG-SM for Caco-2 cells was studied using a standard MTT assay. Figure 6A shows the viability of cells incubated with five different formulations for 24 hours. TCG-CE and TCG-SM exhibited a similar dose-dependent inhibitory effect to raw TCG solution on proliferation of Caco-2 cells. However, formulations without TCG (blank-CE and blank-SM) showed no cytotoxicity on
Caco- 2 cells. These results indicated that the oil, surfactant, and cosurfactant used in SMEDDS were not toxic for Caco-2 cells at the concentration used in the SMEDDS ( $400 \mu \mathrm{g} / \mathrm{mL}$, calculated from the corresponding TCG content), while the raw TCG solution, TCG-CE, and TCG-SM exhibited significant cytotoxicity at concentrations of TCG above $9 \mu \mathrm{g} / \mathrm{mL}$. Interestingly, the cytotoxicity appeared to be associated with the TCG concentration, but not with the formulations. This confirmed that the formulations are highly biocompatible and can be used as drug carriers for oral administration, while TCG-SM displays similar cytotoxic activity in vitro to the commercial TCG formulation (Brilinta) based on the dose of drug. Therefore, further cell studies were performed with formulations containing $9 \mu \mathrm{g} / \mathrm{mL}$ of TCG, a lower concentration than the half-maximal inhibitory concentration of raw TCG solution $(13.1 \pm 2.3 \mu \mathrm{g} / \mathrm{mL})$ calculated from the nonlinear fitted curve.

\section{Cellular uptake study}

To confirm whether the SMEDDS formulation could enhance the uptake of loaded TCG, Caco-2 cells were incubated with raw TCG solution, TCG-CE, or TCG-SM, and their 

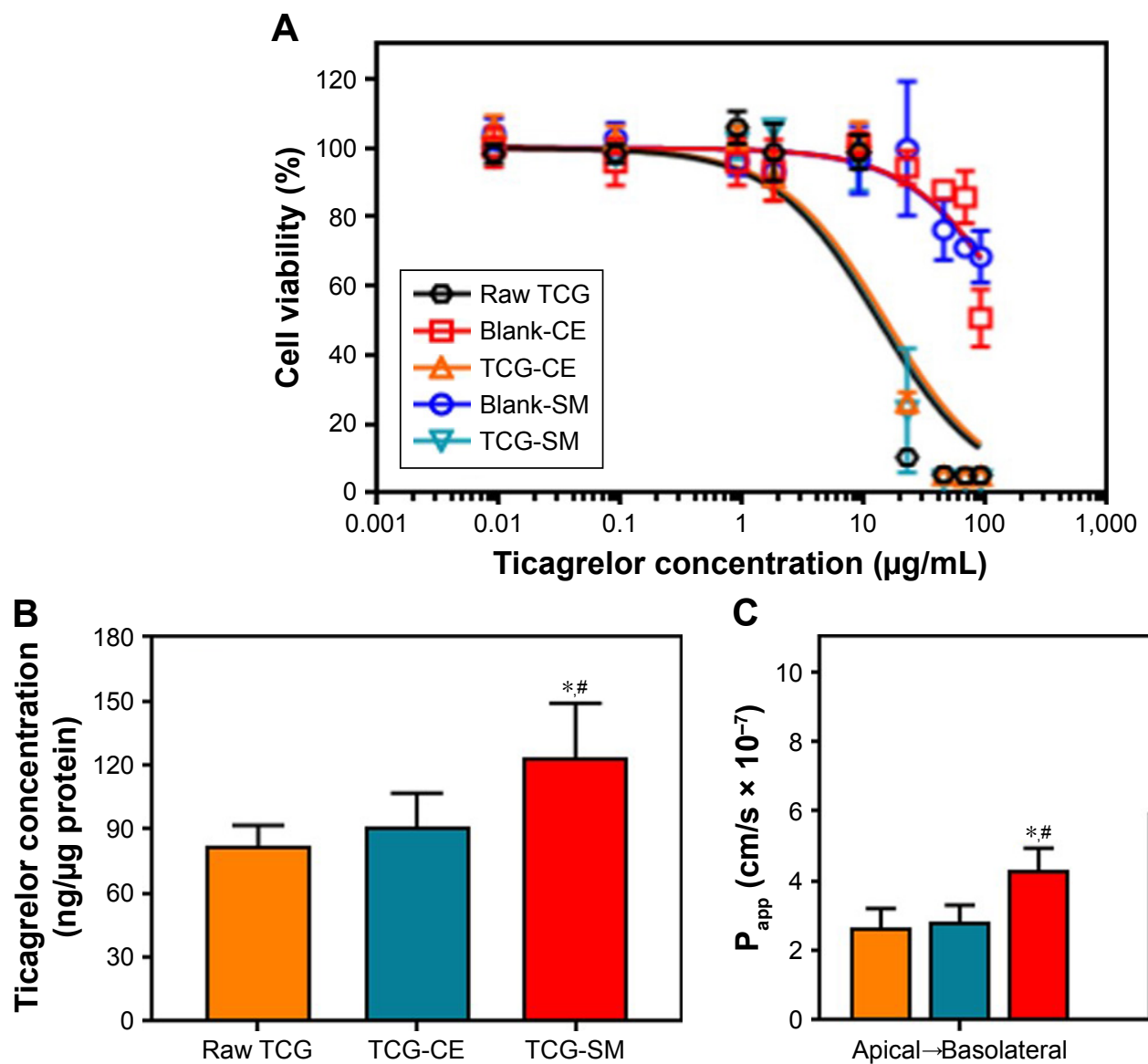

C

\section{$\square$ Raw TCG $\square$ TCG-CE $\square$ TCG-SM}

Figure 6 (A) Cell viability of Caco-2 as a function of TCG corresponding concentration for raw TCG solution, blank-CE, TCG-CE, blank-SM, and TCG-SM. (B) Caco-2 cellular uptake of TCG treated with raw TCG solution, TCG-CE, and TCG-SM after incubation for 4 hours. (C) $P_{\text {app }}$ of raw TCG solution, TCG-CE, and TCG-SM across Caco-2 cell monolayer.

Notes: (A) Values are expressed as mean \pm SD $(n=4)$. (B) Values are expressed as mean $\pm S D(n=4) . * P<0.05$ vs raw TCG solution, ${ }^{\#} P<0.05$ vs TCG-CE. (C) Values are expressed as mean $\pm S D(n=4)$. $* P<0.05$ vs raw TCG solution, ${ }^{P}<0.05$ vs TCG-CE.

Abbreviations: blank-CE, Cremophor EL without ticagrelor; blank-SM, self-microemulsifying drug delivery system without ticagrelor; CE, Cremophor EL; $\mathrm{P}_{\text {app }}$, apparent permeability coefficients; SM, self-microemulsifying drug delivery system; TCG-CE, ticagrelor-loaded Cremophor EL; TCG-SM, ticagrelor-loaded self-microemulsifying drug delivery system; TCG, ticagrelor.

intracellular TCG content was quantified by HPLC analysis. As shown in Figure 6B, Caco-2 cell uptake of TCG from TCG-SM was 1.50 and 1.35 times higher than that from raw TCG solution and TCG-CE, respectively, after incubation for 4 hours $(P<0.05)$. In the case of TCG-CE, the uptake was 1.11 times higher than that of raw TCG solution, but these were not significantly different $(P>0.05)$. Based on these results, we concluded that cell uptake of TCG was improved by TCG-SM.

\section{Permeability test}

Caco-2 cell monolayer models were also established to evaluate the permeability of raw TCG solution, TCG-CE, and TCG-SM. Figure S1 (Supplementary materials) illustrates that the cumulative amount of transported TCG was time-dependent for all formulations. TCG-SM exhibited better transepithelial transport than the other formulations, which was consistent with the analysis of Caco-2 cellular uptake of TCG discussed above. As shown in Figure 6C, the observed mean $\mathrm{P}_{\text {app }}(\mathrm{A}-\mathrm{B})$ values of raw TCG solution, TCG$\mathrm{CE}$, and TCG-SM were $2.64 \times 10^{-7} \mathrm{~cm} / \mathrm{s}, 2.81 \times 10^{-7} \mathrm{~cm} / \mathrm{s}$, and $4.30 \times 10^{-7} \mathrm{~cm} / \mathrm{s}$, respectively. The mean $\mathrm{P}_{\text {app }}(\mathrm{A}-\mathrm{B})$ of TCG in TCG-SM was 1.63 times higher than that of raw TCG solution $(P<0.05)$. Similarly, mean $\mathrm{P}_{\text {app }}(\mathrm{B}-\mathrm{A})$ values of $5.96 \times 10^{-7} \mathrm{~cm} / \mathrm{s}, 5.67 \times 10^{-7} \mathrm{~cm} / \mathrm{s}$, and $7.24 \times 10^{-7} \mathrm{~cm} / \mathrm{s}$ were obtained for raw TCG solution, TCG-CE, and TCG-SM, respectively. The mean $\mathrm{P}_{\text {app }}(\mathrm{B}-\mathrm{A})$ of TCG in TCG-SM was 1.23 times higher than that of the raw TCG solution $(P<0.05)$. This result is probably due to an increase in the drug transported (A-B), thus increasing the level of $\mathrm{B}-\mathrm{A}$ 
Table 5 In vivo pharmacokinetic parameters of TCG in rats after oral administration of raw TCG suspension, TCG-CE, and TCG-SM

\begin{tabular}{|l|l|l|l|}
\hline \multirow{2}{*}{ Pharmacokinetic parameters } & Samples & \multicolumn{2}{l|}{ TCG-SM } \\
\cline { 2 - 4 } & Raw TCG suspension & TCG-CE & $0.75 \pm 0.24$ \\
\hline $\mathrm{T}_{\max }$ (hours) & $1.02 \pm 0.52$ & $0.58 \pm 0.23$ & $439.18 \pm 172.01$ *\#\# \\
\hline $\mathrm{C}_{\max }(\mathrm{ng} / \mathrm{mL})$ & $68.94 \pm 25.67$ & $85.10 \pm 35.57$ & $2,525.29 \pm 390.27^{*, \#}$ \\
\hline $\mathrm{AUC}_{0-\infty}(\mathrm{ng} \cdot \mathrm{h} / \mathrm{mL})$ & $443.26 \pm 147.80$ & $427.25 \pm 153.96$ & $4.34 \pm 2.09$ \\
\hline $\mathrm{T}_{\mathrm{I} / 2}$ (hours) & $5.97 \pm 4.91$ & $3.40 \pm 1.40$ & 637.1 \\
\hline RBA (\%) vs raw TCG suspension & - & 123.4 & \\
\hline
\end{tabular}

Notes: $* P<0.05$ vs raw TCG suspension, ${ }^{*} P<0.05$ vs TCG-CE. Values are expressed as mean \pm SD ( $\left.n=I \mathrm{I}\right)$. “-” indicates compared samples of raw TCG suspension are equal with each other.

Abbreviations: $A \cup C$, area under the concentration-time curve; $C_{\max }$, maximum plasma concentration; $R B A$, relative bioavailability; $T_{\max }$, time to reach the maximum plasma concentration; $T_{1 / 2}$, half-life; TCG, ticagrelor; TCG-CE, ticagrelor-loaded Cremophor EL; TCG-SM, ticagrelor-loaded self-microemulsifying drug delivery system.

transport. Observed ERs were 2.26, 2.02, and 1.68 for raw TCG solution, TCG-CE, and TCG-SM, respectively. The ER of TCG-SM was decreased by $25.7 \%$ compared with that of raw TCG solution. These results support the improved permeability of TCG by a SMEDDS formulation. The enhancement in the $\mathrm{P}_{\text {app }}(\mathrm{A}-\mathrm{B})$ of TCG-SM compared with raw TCG solution and TCG-CE could be due to smaller droplet size and higher lipophilicity for the reconstituted TCG-SM. ${ }^{41}$ These reduced-size droplets containing TCG solubilized by SMEDDS formulation easily permeated across the barrier membrane, which indicates improvement in the apparent permeability, flux, and relative permeability of TCG. In addition, the enhancement of the lipophilicity of TCG by microemulsion increased its adhesion to intestinal membrane, which could be associated with improved drug transport and optimizing intestinal absorption and permeation. ${ }^{42}$ Based on these results, we could confirm the enhancement of the transepithelial permeability of TCG by the SMEDDS formulation.

\section{Pharmacokinetic and pharmacodynamic studies \\ Pharmacokinetic study}

To evaluate the pharmacokinetics of the formulations, samples of raw TCG suspension, TCG-CE, and TCG-SM were orally administered to rats at a dose of $10 \mathrm{mg} / \mathrm{kg}$ TCG. The relevant pharmacokinetic parameters of each formulation are shown in Table 5. $\mathrm{C}_{\max }$ and $\mathrm{AUC}_{0-\infty}$ of TCG after oral administration differed significantly in the following order: TCG-SM $>$ TCG-CE $>$ raw TCG suspension (Figure 7). As expected, raw TCG suspension exhibited poor $\mathrm{C}_{\max }(68.94 \pm 25.67 \mathrm{ng} / \mathrm{mL})$ and $\mathrm{AUC}_{0-\infty}$ (443.26 $\pm 147.80 \mathrm{ng} \cdot \mathrm{h} / \mathrm{mL})$. The TCG-CE exhibited a slightly increased $\mathrm{C}_{\max }(85.10 \pm 35.57 \mathrm{ng} / \mathrm{mL})$, but the $\mathrm{AUC}_{0-\infty}$ $(427.25 \pm 153.96 \mathrm{ng} \cdot \mathrm{h} / \mathrm{mL})$ was similar to that of the raw TCG suspension. However, the $\mathrm{C}_{\max }(439.18 \pm 172.01 \mathrm{ng} / \mathrm{mL})$ and
$\mathrm{AUC}_{0-\infty}(2,525.29 \pm 390.27 \mathrm{ng} \cdot \mathrm{h} / \mathrm{mL})$ of TCG-SM were significantly higher than those of raw TCG suspension and TCGCE $(P<0.05)$. TCG-CE and TCG-SM formulations showed slightly reduced $\mathrm{T}_{\max }$ compared with raw TCG suspension, but the difference was not significant $(P>0.05)$. Therefore, the TCG-SM formulation improved the oral bioavailability of TCG by $637.1 \%$ compared with the raw TCG suspension. The improved oral bioavailability of TCG-SM was correlated with the result of the in vitro dissolution test and cell studies, which showed that TCG-SM was advantageous for achieving increased drug release, higher cellular uptake, and enhanced permeability across the intestinal epithelium.

\section{Pharmacodynamic study}

In vitro antiplatelet activity test

To confirm the antiplatelet activity of TCG and formulations, in vitro antiplatelet activity tests were carried out. The platelet aggregation in the presence of different concentrations of TCG $(5.2,15.7,31.4,261.3,522.6,1,567.7,3,135.4$, and

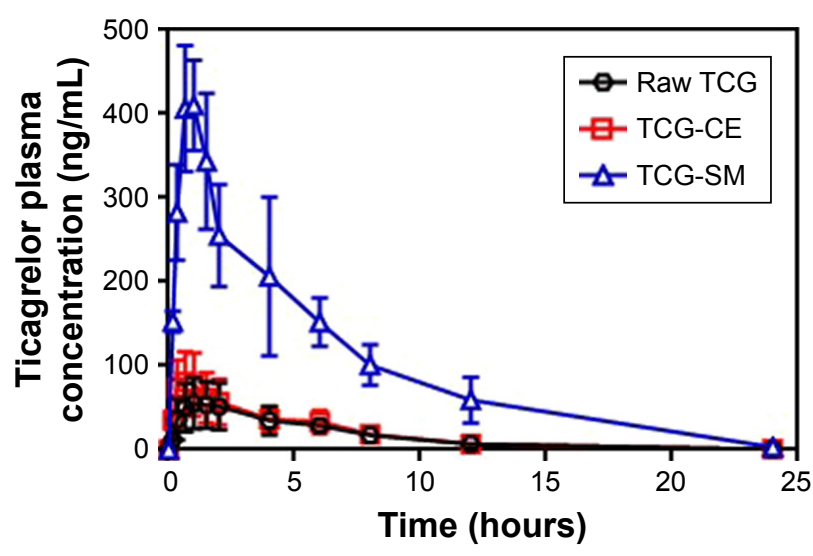

Figure 7 Mean plasma concentration-time profiles of TCG in rats after oral administration of raw TCG suspension, TCG-CE, and TCG-SM at a dose equivalent to $10 \mathrm{mg} / \mathrm{kg}$ of TCG.

Note: Values are expressed as mean \pm SD $(n=I I)$.

Abbreviations: TCG, ticagrelor; TCG-CE, ticagrelor-loaded Cremophor EL; TCG-SM, ticagrelor-loaded self-microemulsifying drug delivery system. 


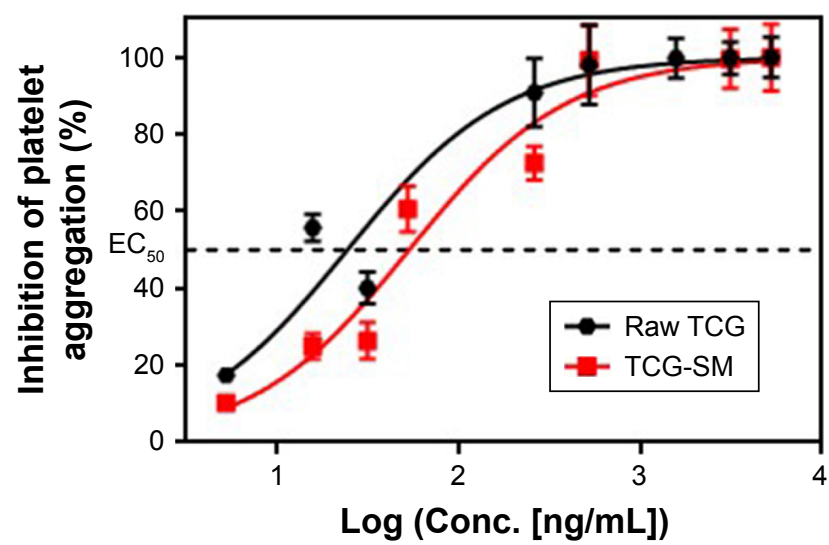

Figure 8 In vitro concentration-response curves for TCG inhibitory actions on ADP-induced platelet aggregations of raw TCG suspension and TCG-SM.

Notes: $\mathrm{EC}_{50}$ was defined as the concentration of the drug that inhibits platelet aggregation to $50 \%$. Values are expressed as mean \pm SEM $(n=3)$.

Abbreviations: $\mathrm{EC}_{50}, 50 \%$ effective concentration; SEM, standard error of mean; TCG, ticagrelor; TCG-SM, ticagrelor-loaded self-microemulsifying drug delivery system.

5,225.7 ng/mL) in raw TCG suspension and TCG-SM diluted with distilled water were measured using an LTA method. Both raw TCG suspension and TCG-SM inhibited platelet aggregation in a dose-dependent manner (Figure 8). In the blank formulations (blank-solution and blank-SM), corresponding to the negative control, mean platelet aggregation induced by $20 \mu \mathrm{M}$ ADP ranged from $56 \%$ to $67 \%$ (data not shown). The responses to different formulations were normalized to platelet aggregation with blank PRP. The mean $\mathrm{EC}_{50}$ values for raw TCG suspension and TCG-SM were $39.45 \mathrm{ng} / \mathrm{mL}$ and $58.39 \mathrm{ng} / \mathrm{mL}$, respectively; ie, the $\mathrm{EC}_{50}$ value of TCG-SM was higher than that of raw TCG suspension. This result was suggested to be because of the influence on platelet aggregation of the excipients used in SMEDDS. Although the excipients used in TCG-SM have not been studied in detail, Poloxamer 188, which is frequently used as a surfactant, inhibits platelet aggregation. ${ }^{43}$ In vitro, it was difficult to confirm the synergistic effect on antiplatelet activity of the SMEDDS formulation because the drug-loaded formulations were added directly to PRP for the assessment of in vitro antiplatelet activity. These results did not allow for the enhancement of absorption of the drug caused by the formulation. Therefore, there was no significant difference in the efficacy of the two formulations. However, further ex vivo studies were performed to assess whether TCG-SM has more potent antiplatelet activity than raw TCG suspension in rats.

\section{Ex vivo antiplatelet activity test}

Ex vivo platelet aggregation was used to evaluate the antiplatelet activity of TCG in different formulations and was measured as the degree of platelet aggregation induced by $20 \mu \mathrm{M}$ ADP in blood samples taken at 1, 2, 5, 10, and 24 hours after oral administration. A dose-related inhibitory effect on platelet aggregation was demonstrated after a single oral administration of raw TCG suspension and TCG-SM (2, 5, and $10 \mathrm{mg} / \mathrm{kg}$ ) (Figure 9A). As indicated in Table 6, the $\mathrm{AUIC}_{0-24}$ data showed that the level of antiplatelet activity of TCG-SM was greater than that of raw TCG suspension at the same drug dose. The $\mathrm{AUIC}_{0-24}$ of the rats treated with 2,5 , and $10 \mathrm{mg} / \mathrm{kg}$ of TCG-SM was $270.4 \% \pm 113.3 \%$ hours, $907.8 \% \pm 200.5 \%$.hours, and $1,254.0 \% \pm 233.9 \% \cdot$ hours, respectively, which was much
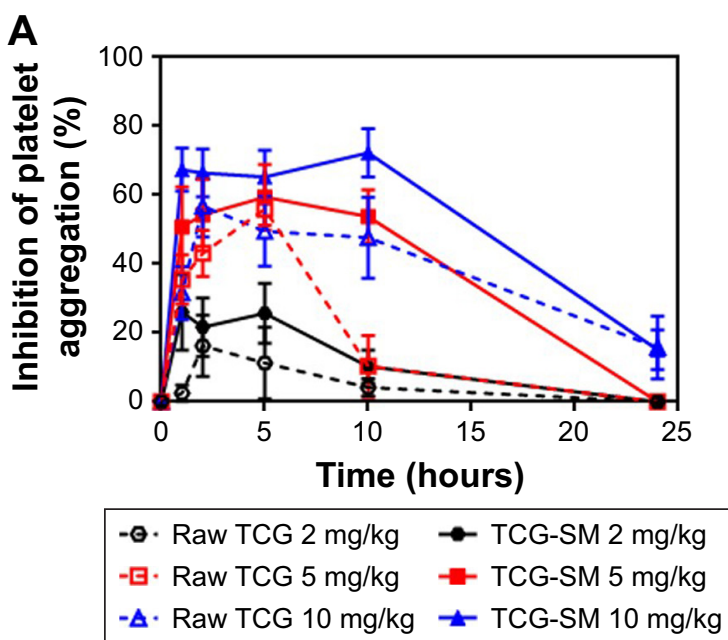

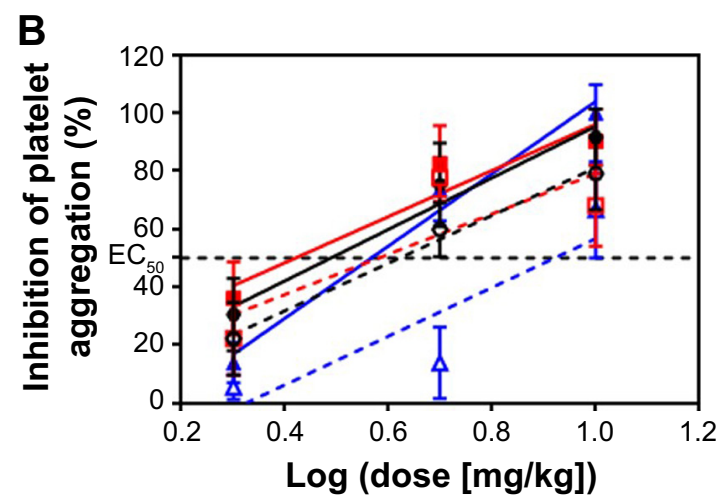

- $\bullet$. Raw TCG at 2 hours $\rightarrow$ TCG-SM at 2 hours

-․ Raw TCG at 5 hours - TCG-SM at 5 hours

-A. Raw TCG at 10 hours $\_$TCG-SM at 10 hours

Figure 9 (A) Ex vivo antiplatelet activity evaluation of raw TCG suspension and TCG-SM according to dose of 2, 5, and $10 \mathrm{mg} / \mathrm{kg}$. (B) Dose-response curve for ADP-induced platelet aggregation in TCG according to time-points (2, 5, and 10 hours) after oral administration of raw TCG suspension and TCG-SM.

Notes: $(\mathbf{A})$ Values are expressed as mean $\pm \operatorname{SEM}(n=9)$. $(\mathbf{B}) \mathrm{ED}_{50}$ was defined as the dose of the drug that inhibits platelet aggregation to $50 \%$. Values are expressed as mean \pm SEM $(n=9)$.

Abbreviations: $\mathrm{ED}_{50}, 50 \%$ effective dose; SEM, standard error of mean; TCG, ticagrelor; TCG-SM, ticagrelor-loaded self-microemulsifying drug delivery system. 
Table 6 Ex vivo pharmacodynamic parameters of TCG in rats after oral administration of raw TCG suspension and TCG-SM with dose of 2,5 , and $10 \mathrm{mg} / \mathrm{kg}$

\begin{tabular}{|c|c|c|c|c|c|}
\hline \multirow[t]{3}{*}{ Samples } & \multirow[t]{3}{*}{ Dose (mg/kg) } & \multicolumn{4}{|c|}{ Pharmacodynamic parameters } \\
\hline & & \multirow[t]{2}{*}{ AUIC $_{0-24}$ (\%.hours) } & \multicolumn{3}{|c|}{$E D_{50}(\mathrm{mg} / \mathrm{kg})$} \\
\hline & & & 2 hours & 5 hours & 10 hours \\
\hline \multirow[t]{3}{*}{ Raw TCG suspension } & 2 & $119.9 \pm 86.7$ & \multirow[t]{3}{*}{5.1} & \multirow[t]{3}{*}{4.5} & \multirow[t]{3}{*}{8.4} \\
\hline & 5 & $444.3 \pm 205.7$ & & & \\
\hline & 10 & $907.0 \pm 408.8$ & & & \\
\hline \multirow[t]{3}{*}{ TCG-SM } & 2 & $270.4 \pm 113.3^{*}$ & \multirow[t]{3}{*}{3.5} & \multirow[t]{3}{*}{2.5} & \multirow[t]{3}{*}{4.4} \\
\hline & 5 & $907.8 \pm 200.5^{*}$ & & & \\
\hline & 10 & $1,254.0 \pm 233.9^{*}$ & & & \\
\hline
\end{tabular}

Notes: $* p<0.05$ vs raw TCG suspension of same dose. Values are expressed as mean $\pm S D(n=9)$.

Abbreviations: AUIC, area under the inhibitory curve; $\mathrm{ED}_{50}, 50 \%$ effective dose; TCG, ticagrelor; TCG-SM, ticagrelor-loaded self-microemulsifying drug delivery system.

higher than in rats treated with raw TCG suspension $(2,5$, and $10 \mathrm{mg} / \mathrm{kg} ; 117.0 \% \pm 88.08 \% \cdot$ hours, $444.3 \% \pm 205.7 \% \cdot$ hours, and $907.0 \% \pm 408.8 \% \cdot$ hours, respectively), demonstrating the significantly improved antiplatelet activity of orally delivered TCG-SM in Sprague Dawley rats. In addition, the raw TCG suspension $(10 \mathrm{mg} / \mathrm{kg})$ exhibited a similar $\mathrm{AUIC}_{0-24}$ (907.0\% $\pm 408.8 \%$.hours) to that of the $5 \mathrm{mg} / \mathrm{kg}$ dose of TCGSM $(907.8 \% \pm 200.5 \%$.hours). These results indicated that the application of the SMEDDS formulation could achieve higher drug efficacy even with a lower dose of drug. We also calculated the $\mathrm{ED}_{50}$ of raw TCG suspension and TCG-SM at various time-points after their administration (Figure 9B and Table 6). The $\mathrm{ED}_{50}$ values for raw TCG suspension at 2, 5, and 10 hours after administration were 5.1, 4.5, and $8.4 \mathrm{mg} / \mathrm{kg}$, respectively, while those of TCG-SM were 3.5 , 2.5 , and $4.4 \mathrm{mg} / \mathrm{kg}$, respectively. The $\mathrm{ED}_{50}$ values of both formulations were lowest at the 5-hour time-point, indicating the time of peak antiplatelet activity. The $\mathrm{ED}_{50}$ values
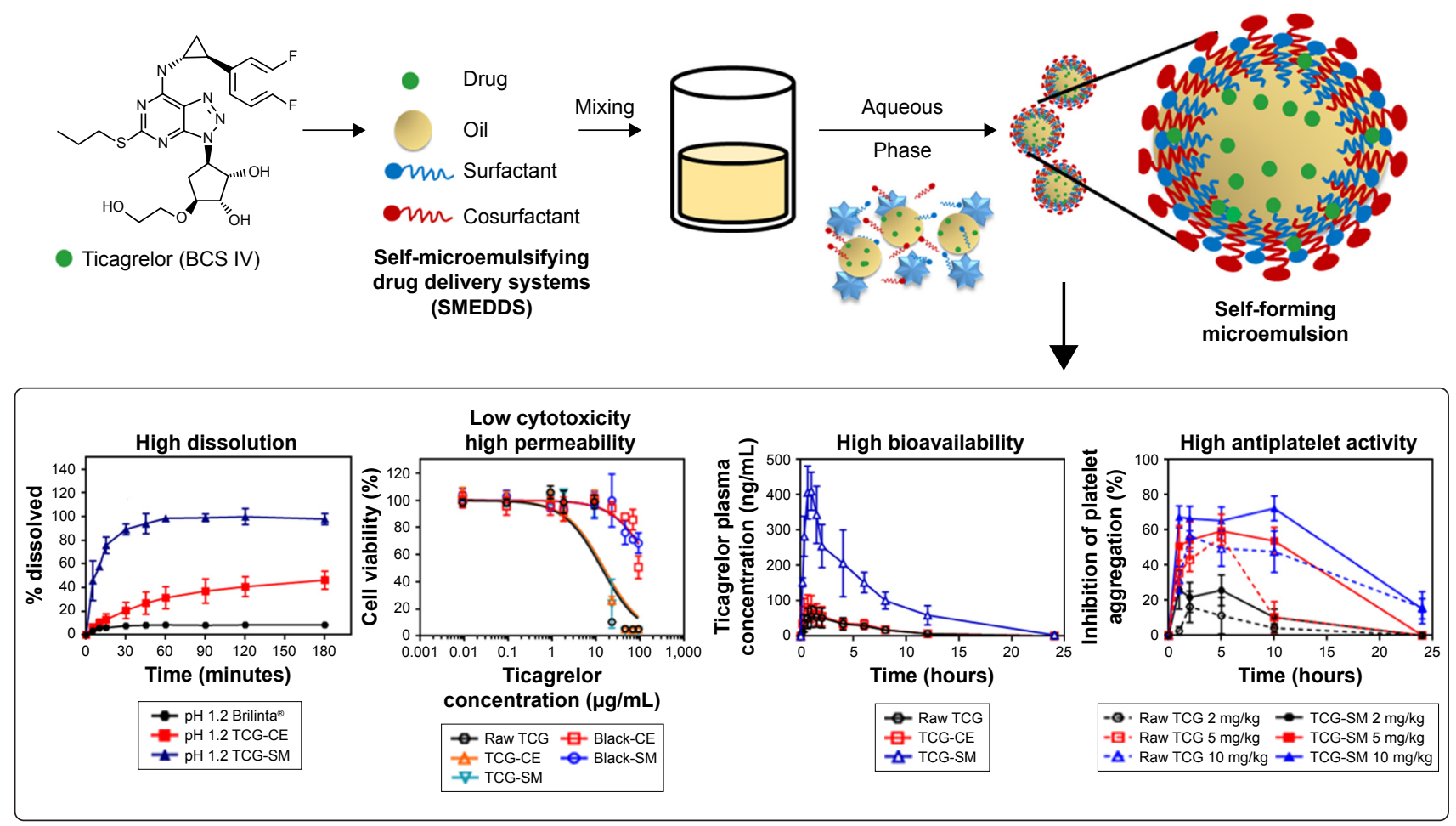

Enhanced antiplatelet activity and bioavailability

Figure 10 Main design and result for the development of TCG-SM.

Abbreviations: BCS, Biopharmaceutical Classification System; blank-CE, Cremophor EL without ticagrelor; blank-SM, self-microemulsifying drug delivery system without ticagrelor; CE, Cremophor EL; TCG, ticagrelor; TCG-SM, ticagrelor-loaded self-microemulsifying drug delivery system. 
of TCG-SM were lower than those of raw TCG suspension at all time-points. These results indicated that TCG-SM not only improved the bioavailability of TCG but also increased its antiplatelet activity by enhancing absorption of the drug.

In summary, the optimized TCG-SM showed high dissolution, low cytotoxicity, and high permeability. These results led to increased bioavailability and antiplatelet activity of TCG (Figure 10).

\section{Conclusion}

The optimized TCG-SM contained 10\% Capmul MCM (oil, $\mathrm{X}_{1}$ ), 53.8\% Cremophor EL (surfactant, $\mathrm{X}_{2}$ ), and 36.2\% Transcutol P (cosurfactant, $\mathrm{X}_{3}$ ). The SMEDDS formulation produced high solubility of TCG, small droplet size, low precipitation, and high transmittance. In addition, the formulation showed higher dissolution profile, improved cellular uptake, and permeability of TCG on Caco- 2 cells. The pharmacokinetic study demonstrated the enhanced bioavailability of TCG in the TCG-SM formulation, and the ex vivo pharmacodynamic study showed that TCG-SM increased the absorption of TCG and showed greater inhibition of platelet aggregation than the same dose of raw TCG suspension. In conclusion, the optimized TCG-SM could be potentially used for improving the antiplatelet activity of TCG at a reduced dose. SMEDDS as a liquid formulation should be placed in a soft gelatin capsule for the development of drug product, which may lead to problems such as capsule aging and high manufacturing costs. So, we will proceed with the solidification study of SMEDDS to make a solid formulation such as a tablet. In addition, we will investigate the integrity of SMEDDS in body and in vitro-in vivo correlation of SMEDDS using GastroPlus program.

\section{Acknowledgments}

This work was supported by the Basic Science Research Program (2016R1A2B4011294) through the National Research Foundation of Korea (NRF) funded by the Ministry of Education, Science and Technology. The sample excipients of Gattefossé Co. and ABITEC Corporations were from the kind support of Masung \& Co., Ltd. We would like to thank DW Yeom for fruitful discussions about the design of experiments study.

\section{Disclosure}

Mr Gi-Ho Son and Mr Ki-Hyun Bang are employed by Korea United Pharmaceutical Co. Ltd., Sejong, Republic of Korea. Mr Sung-Hoon Jeon is employed by SamA Pharmaceutical Co. Ltd., Suwon, Republic of Korea. The authors did not receive grants/funds from these affiliations for this study. The authors report no other conflicts of interest in this work.

\section{References}

1. Husted S, Emanuelsson H, Heptinstall S, Sandset PM, Wickens M, Peters G. Pharmacodynamics, pharmacokinetics, and safety of the oral reversible $\mathrm{P}_{2} \mathrm{Y}_{12}$ antagonist AZD6140 with aspirin in patients with atherosclerosis: a double-blind comparison to clopidogrel with aspirin. Eur Heart J. 2006;27(9):1038-1047.

2. Teng R, Oliver S, Hayes MA, Butler K. Absorption, distribution, metabolism, and excretion of ticagrelor in healthy subjects. Drug Metab Dispos. 2010;38(9):1514-1521.

3. van Giezen JJ, Humphries RG. Preclinical and clinical studies with selective reversible direct $\mathrm{P}_{2} \mathrm{Y}_{12}$ antagonists. Semin Thromb Hemost. 2005;31(02):195-204.

4. Husted S, van Giezen JJJ. Ticagrelor: the first reversibly binding oral P2Y ${ }_{12}$ receptor antagonist. Cardiovas Ther. 2009;27(4):259-274.

5. Wijeyeratne YD, Joshi R, Heptinstall S. Ticagrelor: a P2 $\mathrm{Y}_{12}$ antagonist for use in acute coronary syndromes. Expert Rev Clin Pharmacol. 2012;5(3):257-269.

6. Wallentin L, Becker RC, Budaj A, et al. Ticagrelor versus clopidogrel in patients with acute coronary syndromes. $N$ Engl J Med. 2009; 361(11):1045-1057.

7. BRILINTA (ticagrelor) [package insert]. Wilmington, DE: AstraZeneca Pharmaceuticals LP; 2016.

8. Ramesh K, Shekar C, Khadgapathi P. Enhancement of solubility and rate of in vitro drug release profiles of poorly soluble ticagrelor by solvent evaporation solid dispersion technique. Indo Am J Pharm Res. 2015;5(12):3850-3858.

9. Pai G, Sathyanarayana MB. Fabrication and solid state characterization of ticagrelor co-crystals with improved solubility and dissolution. Int $J$ Pharm Qual Assur. 2017;8(1):1-8.

10. Chen ZQ, Liu Y, Zhao JH, Wang L, Feng NP. Improved oral bioavailability of poorly water-soluble indirubin by a supersaturatable self-microemulsifying drug delivery system. Int J Nanomedicine. 2012;7:1115-1125.

11. Kamboj S, Sharma R, Singh K, Rana V. Aprepitant loaded solid preconcentrated microemulsion for enhanced bioavailability: a comparison with micronized aprepitant. Eur J Pharm Sci. 2015;78:90-102.

12. Yeom DW, Song YS, Kim SR, et al. Development and optimization of a self-microemulsifying drug delivery system for atorvastatin calcium by using D-optimal mixture design. Int J Nanomedicine. 2015; 10:3865-3878.

13. Yeom DW, Chae BR, Son HY, et al. Enhanced oral bioavailability of valsartan using a polymer-based supersaturable self-microemulsifying drug delivery system. Int J Nanomedicine. 2017;12:3533-3545.

14. Patel G, Shelat P, Lalwani A. Statistical modeling, optimization and characterization of solid self-nanoemulsifying drug delivery system of lopinavir using design of experiment. Drug Deliv. 2016;23(8): 3027-3042.

15. Kamboj S, Rana V. Quality-by-design based development of a selfmicroemulsifying drug delivery system to reduce the effect of food on nelfinavir mesylate. Int J Pharm. 2016;501(1-2):311-325.

16. Elnaggar YS, El-Massik MA, Abdallah OY. Self-nanoemulsifying drug delivery systems of tamoxifen citrate: design and optimization. Int $J$ Pharm. 2009;380(1-2):133-141.

17. Porter CJ, Pouton CW, Cuine JF, Charman WN. Enhancing intestinal drug solubilisation using lipid-based delivery systems. Adv Drug Deliv Rev. 2008;60(6):673-691.

18. Porter CJH, Charman WN. In vitro assessment of oral lipid based formulations. Adv Drug Deliv Rev. 2001;50(Suppl 1):S127-S147.

19. Balakrishnan P, Lee BJ, Oh DH, et al. Enhanced oral bioavailability of coenzyme Q10 by self-emulsifying drug delivery systems. Int J Pharm. 2009;374(1-2):66-72.

20. Dixit AR, Rajput SJ, Patel SG. Preparation and bioavailability assessment of SMEDDS containing valsartan. AAPS Pharm Sci Tech. 2010; 11(1):314-321.

21. Krishnamoorthy B, Habibur Rahman SM, Tamil Selvan N, et al. Design, formulation, in vitro, in vivo, and pharmacokinetic evaluation of nisoldipine-loaded self-nanoemulsifying drug delivery system. J Nanopart Res. 2015;17(1):34. 
22. Bueno LM, Manoel JW, Giordani CF, et al. HPLC method for simultaneous analysis of ticagrelor and its organic impurities and identification of two major photodegradation products. Eur J Pharm Sci. 2017;97:22-29.

23. Pouton CW. Formulation of poorly water-soluble drugs for oral administration: physicochemical and physiological issues and the lipid formulation classification system. Eur J Pharm Sci. 2006;29(3-4):278-287.

24. Scheffé H. Experiments with mixtures. J R Stat Soc Series B. 1958; 20(2):344-360.

25. Gurram AK, Deshpande PB, Kar SS, Nayak UY, Udupa N, Reddy MS. Role of components in the formation of self-microemulsifying drug delivery systems. Indian J Pharm Sci. 2015;77(3):249-257.

26. Hall S, Pacek AW, Kowalski AJ, Cooke M, Rothman D. The effect of scale and interfacial tension on liquid-liquid dispersion in in-line Silverson rotor-stator mixers. Chem Eng Res Des. 2013;91(11):2156-2168.

27. Lu Y, Park K. Polymeric micelles and alternative nanonized delivery vehicles for poorly soluble drugs. Int J Pharm. 2013;453(1):198-214.

28. Jaiswal P, Aggarwal G, Harikumar SL, Singh K. Development of self-microemulsifying drug delivery system and solid-selfmicroemulsifying drug delivery system of telmisartan. Int J Pharm Investig. 2014;4(4):195-206.

29. Akula S, Gurram AK, Devireddy SR. Self-microemulsifying drug delivery systems: an attractive strategy for enhanced therapeutic profile. Int Sch Res Notices. 2014;2014:964051.

30. Xu W, Ling P, Zhang T. Polymeric micelles, a promising drug delivery system to enhance bioavailability of poorly water-soluble drugs. J Drug Deliv. 2013;2013:340315.

31. Mcshane BB, Gal D. Statistical significance and the dichotomization of evidence. J Am Stat Assoc. 2017;112(519):885-895.

32. Mourabet M, El Rhilassi A, El Boujaady H, Bennani-Ziatni M, Taitai A. Use of response surface methodology for optimization of fluoride adsorption in an aqueous solution by Brushite. Arab J Chem. 2017;10: S3292-S3302.
33. Schneider AA, Hommel G, Blettner M. Linear regression analysis: part 14 of a series on evaluation of scientific publications. Dtsch Ärztebl Int. 2010;107(44):776-782.

34. Bewick V, Cheek L, Ball J. Statistics review 7: correlation and regression. Crit Care. 2003;7(6):451-459.

35. Patel DV. Preparation and evaluation of extended release pellets of chiral molecules of s-metoprolol succinate by different technology. Asian J Pharm. 2017;11(3):210-223.

36. Figueiredo Filho DB, Silva Júnior JA, Rocha EC. What is $\mathrm{R}^{2}$ all about? Leviathan. 2011;3(3):60-68.

37. Balata GF, Essa EA, Shamardl HA, Zaidan SH, Abourehab MA. Selfemulsifying drug delivery systems as a tool to improve solubility and bioavailability of resveratrol. Drug Des Devel Ther. 2016;10:117-128.

38. Zhou H, Wan J, Wu L, et al. A new strategy for enhancing the oral bioavailability of drugs with poor water-solubility and low liposolubility based on phospholipid complex and supersaturated SEDDS. PLoS One. 2013;8(12):e84530.

39. Patel D, Sawant K. Self micro-emulsifying drug delivery system: formulation development and biopharmaceutical evaluation of lipophilic drugs. Curr Drug Deliv. 2009;6(4):419-424.

40. Taha EI, Al-Saidan S, Samy AM, Khan MA. Preparation and in vitro characterization of self-nanoemulsified drug delivery system (SNEDDS) of all-trans-retinol acetate. Int J Pharm. 2004;285(1-2):109-119.

41. Nekkanti V, Karatgi P, Prabhu R, Pillai R. Solid self-microemulsifying formulation for candesartan cilexetil. AAPS PharmSciTech. 2010; 11(1):9-17.

42. Memvanga PB, Eloy P, Gaigneaux EM, Préat V. In vitro lipolysis and intestinal transport of $\beta$-arteether-loaded lipid-based drug delivery systems. Pharm Res. 2013;30(10):2694-2705.

43. Edwards CM, May JA, Heptinstall S, Lowe KC. Effects of pluronic F-68 (poloxamer 188) on platelet aggregation in human whole blood. Thromb Res. 1996;81(4):511-512. 


\section{Supplementary materials}

Table SI The classification standards of emulsification grade

\begin{tabular}{|l|l|l|l|l|}
\hline Grade & $\begin{array}{l}\text { Degree of } \\
\text { emulsification }\end{array}$ & Droplet size (nm) & Transmittance (\%) & Appearance \\
\hline A & Excellent & $<100$ & $>95$ & Clear and transparent \\
\hline B & Good & $100-300$ & $90-95$ & Slightly less clear \\
\hline C & Fair & $300-500$ & $75-90$ & Bluish white \\
\hline D & Poor & $>500$ & $<75$ & Milky \\
\hline
\end{tabular}

Table S2 Coefficient equations of responses according to the level of factors

\begin{tabular}{|l|l|}
\hline Responses & Coefficient equations \\
\hline$Y_{1}$ & $88.84 X_{1}+163.03 X_{2}+321.54 X_{3}$ \\
\hline$Y_{2}$ & $10.13 X_{1}+12.67 X_{2}+60.77 X_{3}+15.91 X_{1} X_{2}-96.06 X_{1} X_{3}-86.73 X_{2} X_{3}$ \\
\hline$Y_{3}$ & $47,658.7 I X_{1}+53.30 X_{2}+965.3 I X_{3}-90,213.26 X_{1} X_{2}-85,963.82 X_{1} X_{3}-1,304.24 X_{2} X_{3}+97,272.7 I X_{1} X_{2} X_{3}-$ \\
& $53,069.49 X_{1} X_{2}\left(X_{1}-X_{2}\right)-43,8 I 4.17 X_{1} X_{3}\left(X_{1}-X_{3}\right)+468.88 X_{2} X_{3}\left(X_{2}-X_{3}\right)$ \\
\hline$Y_{4}$ & $100.75 X_{1}+99.57 X_{2}+48.88 X_{3}-28.52 X_{1} X_{2}-47.4 I X_{1} X_{3}-62.62 X_{2} X_{3}-1453.67 X_{1}^{2} X_{2} X_{3}+1025.35 X_{1} X_{2}^{2} X_{3}-$ \\
& $652.61 X_{1} X_{2} X_{3}^{2}$ \\
\hline
\end{tabular}

Table S3 The experimental composition and observed responses through Scheffés mixture design

\begin{tabular}{|c|c|c|c|c|c|c|c|}
\hline \multirow[t]{3}{*}{ Run } & \multicolumn{3}{|l|}{ Factors } & \multicolumn{4}{|l|}{ Responses } \\
\hline & $x_{1}$ & $x_{2}$ & $x_{3}$ & $\mathbf{Y}_{1}$ & $\mathbf{Y}_{2}$ & $\mathbf{Y}_{3}$ & $\mathbf{Y}_{4}$ \\
\hline & $\begin{array}{l}\text { Capmul MCM } \\
\text { (w/w \%) }\end{array}$ & $\begin{array}{l}\text { Cremophor EL } \\
\text { (w/w \%) }\end{array}$ & $\begin{array}{l}\text { Transcutol P } \\
\text { (w/w \%) }\end{array}$ & $\begin{array}{l}\text { Solubility } \\
\text { (mg/mL) }\end{array}$ & $\begin{array}{l}\text { Precipitation } \\
\text { (\%) }\end{array}$ & $\begin{array}{l}\text { Droplet size } \\
(\mathrm{nm})\end{array}$ & $\begin{array}{l}\text { Transmittance } \\
\text { (\%) }\end{array}$ \\
\hline I & 24.8307 & 65.1693 & 10 & $169.4 \pm 0.93$ & $30.9 \pm 11.2$ & $152.3 \pm 12.4$ & $96.7 \pm 0.02$ \\
\hline 2 & 10 & 25.8795 & 64.1205 & $279.1 \pm 1.94$ & $17.2 \pm 0.9$ & $525.9 \pm 23.8$ & $66.1 \pm 0.59$ \\
\hline 3 & 10 & 10 & 80 & $330.59 \pm 0.93$ & $66.3 \pm 0.9$ & $894.9 \pm 34.1$ & $49.5 \pm 0.37$ \\
\hline 4 & 24.9753 & 46.7603 & 28.2644 & $|88.7 \pm 0.9|$ & $9.4 \pm 0.4$ & $218.3 \pm 14.8$ & $89.2 \pm 0.11$ \\
\hline 5 & 38.6 & 38.2553 & 23.1447 & $165 \pm 3.85$ & $13.1 \pm 0.4$ & $306.7 \pm 25.6$ & $79.6 \pm 0.48$ \\
\hline 6 & 10 & 10 & 80 & $316.05 \pm 3.55$ & $67.7 \pm 0.3$ & I,023.6 $\pm 85 . \mathrm{I}$ & $50.3 \pm 0.52$ \\
\hline 7 & 10 & 62.3288 & 27.6712 & $211.71 \pm 2.63$ & $21.7 \pm 0.4$ & $98.8 \pm 5.7$ & $98.4 \pm 0.06$ \\
\hline 8 & 24.9753 & 46.7603 & 28.2644 & $194.85 \pm 1.76$ & $16.5 \pm 1.5$ & $214.7 \pm 15.6$ & $89.2 \pm 0.06$ \\
\hline 9 & 40 & 50 & 10 & $126.5 \mid \pm 1.98$ & $7.2 \pm 0.4$ & $234.6 \pm 21.4$ & $92.9 \pm 0.10$ \\
\hline 10 & 10 & 80 & 10 & $148.28 \pm 2.67$ & $6.3 \pm 0.3$ & $54.7 \pm 8.6$ & $99.2 \pm 0.02$ \\
\hline II & 24.8307 & 65.1693 & 10 & $129.27 \pm 3.39$ & $0.2 \pm 3.2$ & $189.5 \pm 11.9$ & $93.1 \pm 0.04$ \\
\hline 12 & 32.9684 & 10 & 57.0316 & $237.49 \pm 2.70$ & $18.8 \pm 0.4$ & $631.8 \pm 32.2$ & $54.8 \pm 0.42$ \\
\hline 13 & 23.9412 & 27.95 & 48.1089 & $254.79 \pm 1.41$ & $13.6 \pm 0.0$ & $372.3 \pm 24.7$ & $64.9 \pm 0.35$ \\
\hline 14 & 32.9684 & 10 & 57.0316 & $231.22 \pm 2.66$ & $21 \pm 0.1$ & $686.2 \pm 34.5$ & $56.3 \pm 0.28$ \\
\hline 15 & 10 & 45.642 & 44.358 & $239.32 \pm 1.42$ & $12.2 \pm 0.4$ & $|29.9 \pm 1| .8$ & $94.1 \pm 0.11$ \\
\hline 16 & 40 & 25.75 & 34.25 & $191.07 \pm 1.32$ & $16.2 \pm 0.3$ & $884.0 \pm 64.8$ & $55.3 \pm 0.43$ \\
\hline 17 & 24.9753 & 46.7603 & 28.2644 & $187.13 \pm 2.60$ & $7.0 \pm 0.2$ & $225.8 \pm 21.0$ & $93.2 \pm 0.07$ \\
\hline
\end{tabular}

Note: Values are expressed as mean \pm SD $(n=3)$. 

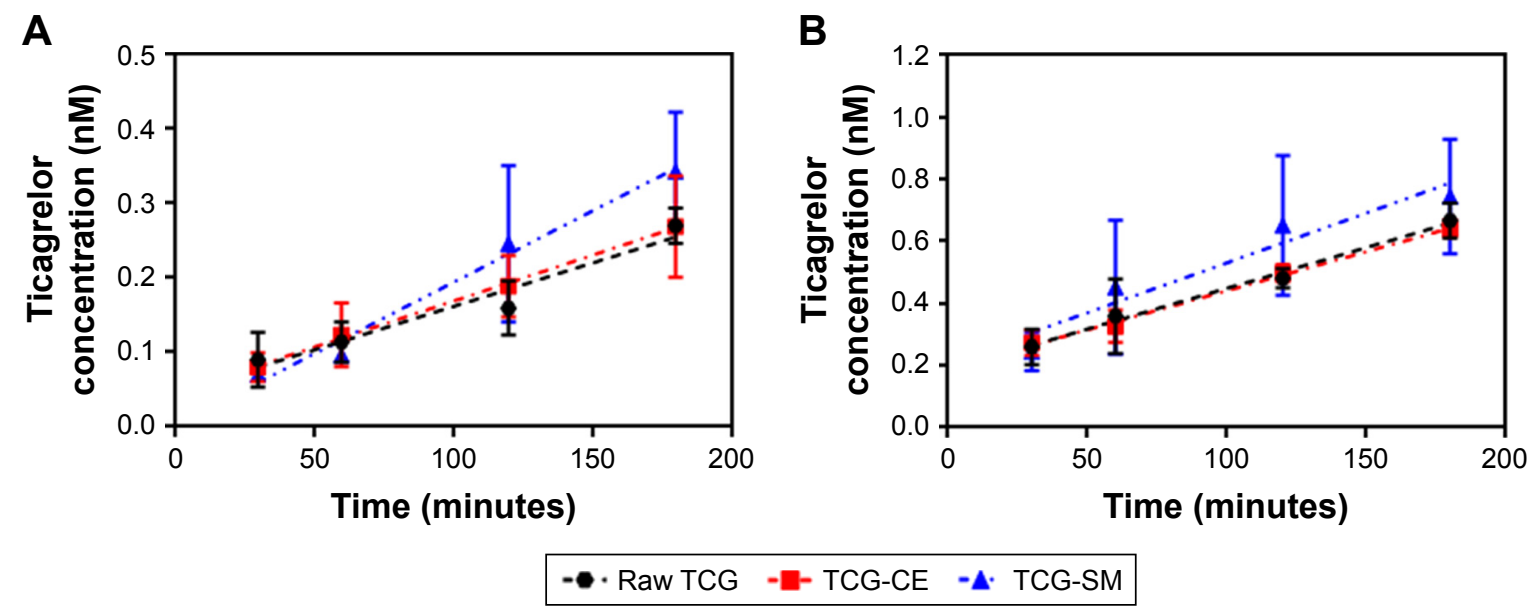

Figure SI (A) Apical-basolateral (A-B) transport of TCG across Caco-2 cell monolayer for 180 minutes. (B) Basolateral-apical (B-A) transport of TCG across Caco-2 cell monolayer for 180 minutes.

Notes: Values are expressed as mean \pm SD $(n=4)$.

Abbreviations: TCG, ticagrelor; TCG-CE, ticagrelor-loaded Cremophor EL; TCG-SM, ticagrelor-loaded self-microemulsifying drug delivery system.

\section{Publish your work in this journal}

The International Journal of Nanomedicine is an international, peerreviewed journal focusing on the application of nanotechnology in diagnostics, therapeutics, and drug delivery systems throughout the biomedical field. This journal is indexed on PubMed Central, MedLine, CAS, SciSearch $®$, Current Contents ${ }^{\circledR} /$ Clinical Medicine,
Journal Citation Reports/Science Edition, EMBase, Scopus and the Elsevier Bibliographic databases. The manuscript management system is completely online and includes a very quick and fair peer-review system, which is all easy to use. Visit http://www.dovepress.com/ testimonials.php to read real quotes from published authors. 